\title{
THE IMPACT OF LANE CLOSURES ON CONGESTION AND RELIABILITY: A CASE STUDY OF TORONTO'S GARDINER EXPRESSWAY
}

\author{
by \\ Christina Borowiec \\ Honours Bachelor of Arts, McMaster University, 2015 \\ A Major Research Paper \\ presented to Ryerson University \\ in partial fulfillment of the requirements for the degree of \\ Master of Planning \\ in \\ Urban Development
}

Toronto, Ontario, Canada, 2017

(C) Christina Borowiec 2017 


\section{AUTHOR'S DECLARATION}

I hereby declare that I am the sole author of this MRP. This is a true copy of the MRP, including any required final revisions. I authorize Ryerson University to lend this MRP to other institutions or individuals for the purpose of scholarly research. I further authorize Ryerson University to reproduce this MRP by photocopying or by other means, in total or in part, at the request of other institutions or individuals for the purpose of scholarly research. I understand that my MRP may be made electronically available to the public. 


\title{
THE IMPACT OF LANE CLOSURES ON CONGESTION AND RELIABILITY: A CASE STUDY OF TORONTO'S GARDINER EXPRESSWAY
}

\author{
(C) Christina Borowiec 2017 \\ Master of Planning \\ in \\ Urban Development \\ Ryerson University
}

\begin{abstract}
Usage of big data with before-after methods of analysis makes it possible to evaluate the effect of major transport investments on system performance. In employing before-after methods to investigate the impact of lane closures on congestion and travel reliability, changes and trade-offs in performance indicators are quantified and policy action effectiveness is evaluated. This is illustrated through a case study of two separate lane closure interventions on the Gardiner Expressway in Toronto, Ontario. Models using a regression framework were developed for the pre-, peri-, and post-closure test periods of the first intervention and pre- and peri-closure periods of the second intervention. Results suggest the impacts of policy actions on system performance are strong, and that congestion and travel reliability counterintuitively move in different directions. Reduced demand effects are observed, prompting discussion on how highways and congestion should be managed and whether or not municipalities should add capacity to regional assets.
\end{abstract}

Key Words:

congestion, travel reliability, before-after methods, lane closures, transportation planning, big data 


\section{ACKNOWLEDGEMENTS}

This research directly contributed to the Gardiner Expressway Performance, Safety, and Reliability study within the Before-After Methods: Transportation Policy and Performance in Toronto report, and was therefore supported by the City of Toronto Transportation Services Division. The report was produced by the School of Urban and Regional Planning at Ryerson University, with Dr. Matthias Sweet and I as authors of the Gardiner Expressway component.

Comments on earlier drafts from Professor Raktim Mitra are appreciated, as they provided helpful feedback and improved this paper.

Special thanks to Dr. Matthias Sweet, who supervised this research and provided valuable insight and expertise, and ongoing guidance and support. 
"Building more roads to prevent congestion is like a fat man loosening his belt to prevent obesity."

- Lewis Mumford, 1955 


\section{TABLE OF CONTENTS}

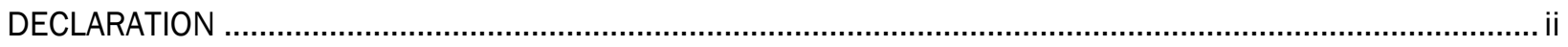

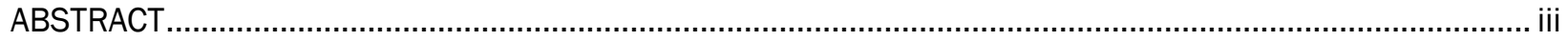

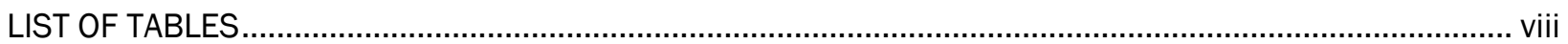

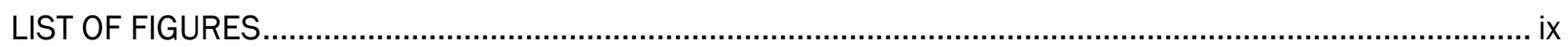

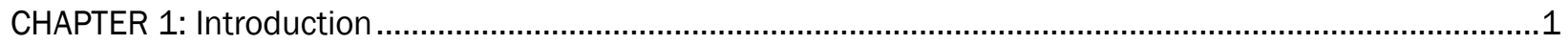

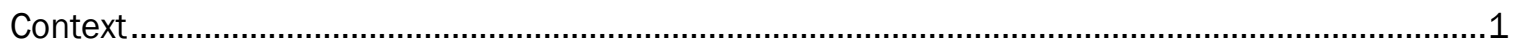

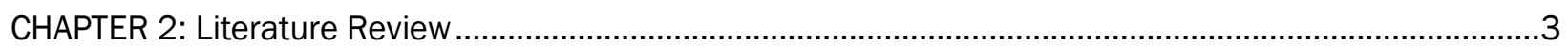

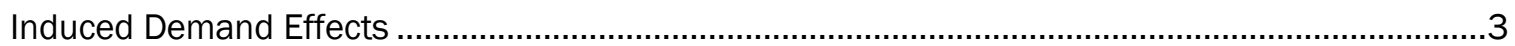

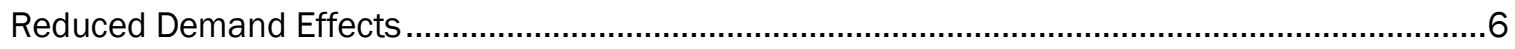

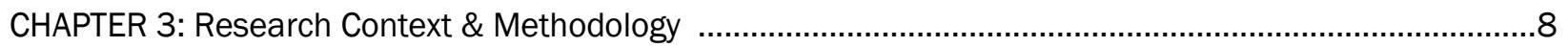

The Gardiner Expressway and Asset Management Challenges .....................................................8

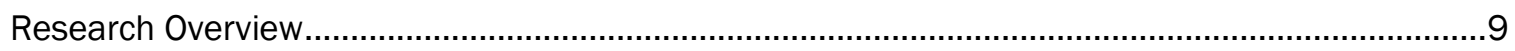

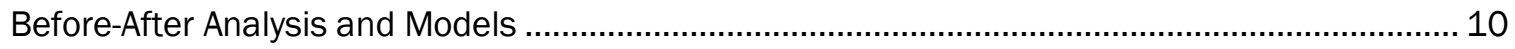

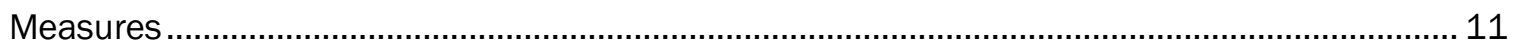

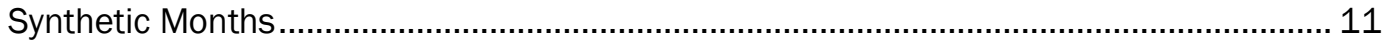

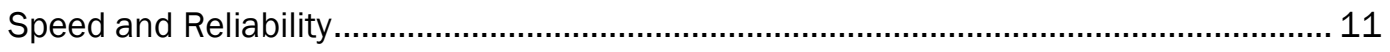

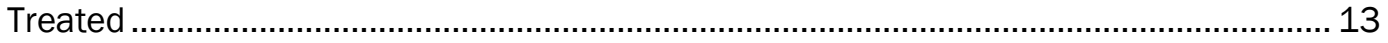

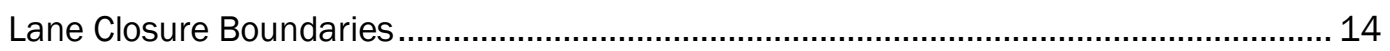

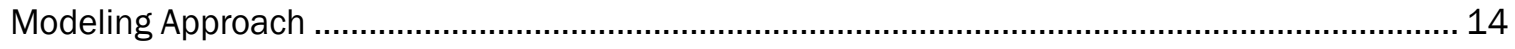

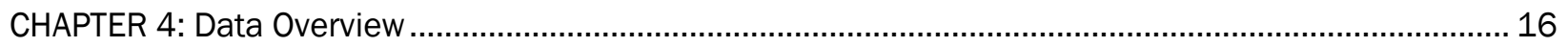

Gardiner Expressway vs. Highway 401 vs. City of Toronto Highways ........................................... 16

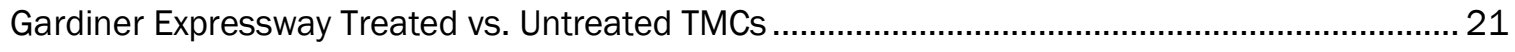




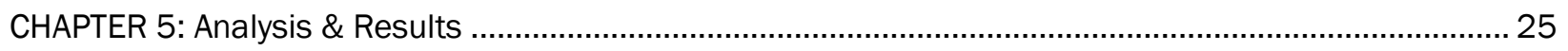

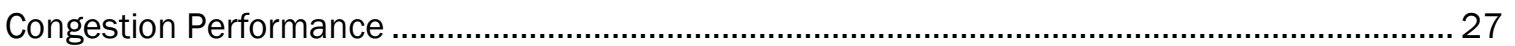

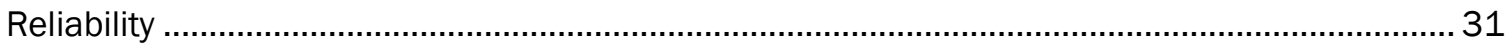

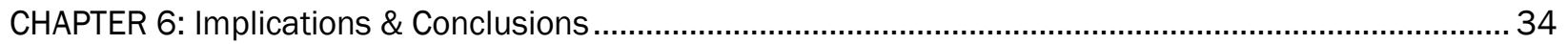

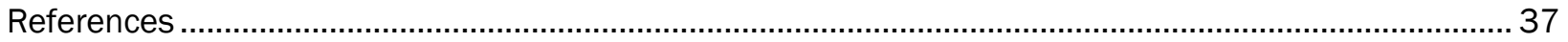




\section{LIST OF TABLES}

Table 1: Periods for Intervention Pre-, Peri-, and Post-Closure Tests ......................................................... 10

Table 2: Experimental and Control Groups for Models ….................................................................... 10

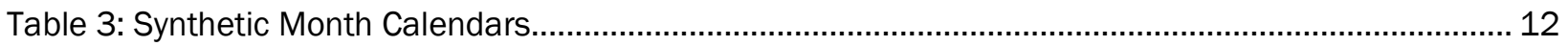

Table 4: Average Speeds (mph) and BTIs: Monday to Friday, 5AM - 9PM ................................................ 17

Table 5: Intervention 1: Average Speeds (AVG) (mph) and BTIs: Monday to Friday, 5AM - 9PM ............. 24

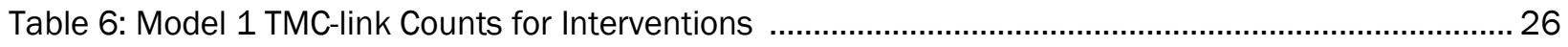

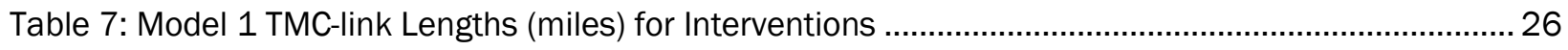

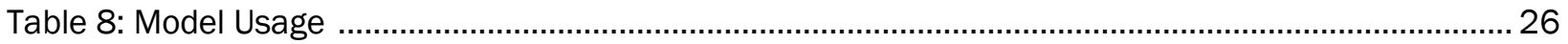

Table 9: Average Change in Speed (\%) between the Control Group and Experimental Group ................... 27

Table 10: Average Change in Buffer Time Index (\%) between Control and Experimental Groups .............. 31 


\section{LIST OF FIGURES}

Figure 1: How Road Capacity Expansion Generates Traffic........................................................................2

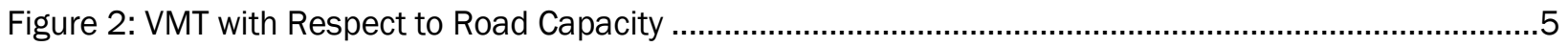

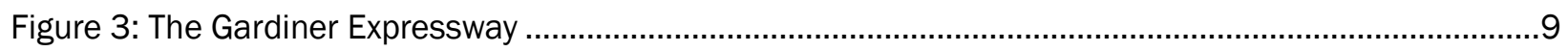

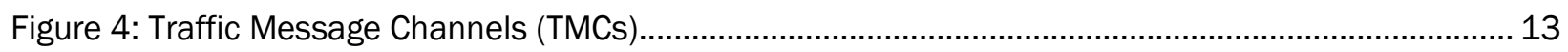

Figure 5: Intervention 1: Gardiner Expressway Treated and Untreated Sections..................................... 14

Figure 6: Intervention 2: Gardiner Expressway Treated and Untreated Sections..................................... 14

Figure 7: Average Monthly Speed: Gardiner vs. Highway 401 vs. City of Toronto Highways ...................... 18

Figure 8: Average Hourly Speed: Gardiner vs. Highway 401 vs. City of Toronto Highways ........................ 18

Figure 9: Average Monthly BTI: Gardiner vs. Highway 401 vs. City of Toronto Highways........................... 19

Figure 10: Average Hourly BTI: City of Toronto Highways, 2014-2016 .................................................. 19

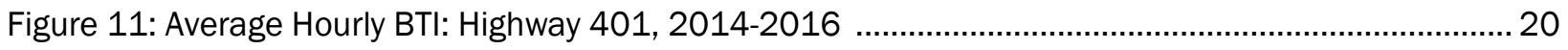

Figure 12: Average Hourly BTI: Gardiner Expressway, 2014-2016 ...................................................... 20

Figure 13: Intervention 1: Average Monthly Speed: Treated vs. Untreated TMCs.................................... 22

Figure 14: Intervention 2: Average Monthly Speed: Treated vs. Untreated TMCs.................................... 22

Figure 15: Intervention 1: Average BTI: Treated vs. Untreated TMCs...................................................... 23

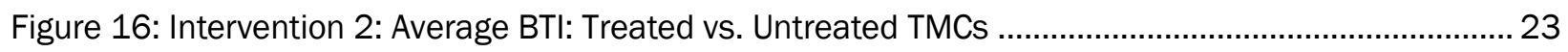

Figure 17: Intervention 1: Average Speed - Average vs. Treated Trends ................................................. 29

Figure 18: Intervention 1: Peak-AM \& Peak-PM Speed - Average vs. Treated Trends ............................. 29

Figure 19: Intervention 2: Average Speed - Average vs. Treated Trends .............................................. 30

Figure 20: Intervention 2: Peak-AM \& Peak-PM Speed - Average vs. Treated Trends .............................. 30

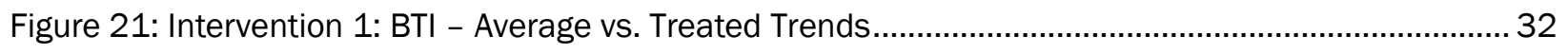

Figure 22: Intervention 1: Peak-AM \& Peak-PM BTI - Average vs. Treated Trends .................................. 32

Figure 23: Intervention 2: BTI - Average vs. Treated Trends.................................................................... 33

Figure 24: Intervention 2: Peak-AM \& Peak-PM BTI - Average vs. Treated Trends..................................... 33 


\section{CHAPTER 1: Introduction}

Independence, freedom of choice, and convenience are doctrines of automobility, which have galvanized the sprawl of cities and consequential construction of highways and roadways to improve connectivity. Policymakers continue to struggle to balance the societal benefits and costs of car usage, including: land use, road maintenance, congestion, noise, environmental degradation, and public health. Although highways enable faster travel between destinations, this benefit is lost when capacity is filled and congestion ensues. Adding more capacity induces travel demand (Litman, 2017), demonstrating that building more highways neither solves traffic congestion nor remedies long-term climate change objectives. Divesting from highways and increasing investment in public transit, active transportation infrastructure, and urban renewal has been explored in several projects, including the West Side Highway in New York and Harbour Drive Expressway in Portland. Although it is understood that new highways induce more users to drive, whether or not travel demand dissipates in response to a reduction in highway capacity is uncertain. Proponents of highways contend that a major reduction in capacity would result in colossal congestion and transportation service consequences. However, advocates for transitoriented urban futures disagree, reasoning that a reduction in highway capacity is likely to lead to less traffic in the long-term, thereby contributing to a more sustainable future. This debate lays at the heart of modern discussions between urban planners and policymakers on the development and management of transportation infrastructure.

\section{Context}

Early $20^{\text {th }}$ century ideologies that endorsed the growth of automotive cities in the 1920 s and the development of the suburbs in the 1940 s through to early 1960 s, are now contested in 21 st century planning. An urban transformation is occurring, characterized by the rise of cities, fall of cars, and “unlocking the grid" movements (Schwartz, 2015). As projects championing sustainability, complete streets, walkability, active transportation, and urban revitalization grow, planning is becoming an increasingly democratic process, wherein a single faction of a population is not given precedence over another. In other words, planning is no longer automobile-oriented. Nonetheless, even with this shift in planning practice, the decisions of the past have led to challenges today - particularly in highway congestion management strategies. Traditionally, traffic jams and gridlock were viewed as problems for which new roads and lane additions were intuitive solutions. Expanding road capacity was likened to replacing a small pipe with a larger one, wherein water can more easily flow through the system (Mann, 2014). However, today it is agreed that traffic cannot be modeled and construed as a liquid. It does not steadily flow through the city along highways, arterials, and local roads; rather, it expands and contracts, like a gas, to fill available space (Jacobsen, 1997). 
On an uncongested highway, traffic grows until capacity is reached and a self-limiting equilibrium is achieved, at which point further growth in vehicle travel is discouraged. When there is an increase in road capacity, the short-term congestion relief improves traffic flow and travel times, thereby making driving more attractive. As such, new trips which may have otherwise not have been made occur, and previously suppressed latent demand materializes as road usage. Traffic is generated and grows to fill the added roadway capacity (Figure 1). This cycle continues indefinitely, with more traffic being generated over time (Downs, 1962; Goodwin, 1996; Litman, 2017; Boarnet \& Chalermpong, 2000). This effect is known as the phenomenon of induced demand, wherein the increase in the supply of a good results in greater consumption of that good. For highways, the "supply" is the road's capacity, and vehiclekilometers or vehicle-miles travelled (VKT and VMT) are the quantity which is "consumed". Much empirical evidence of induced demand effects on highway system performance exists, with the consensus that an increase in highway capacity results in an increase in vehicle miles traveled. Despite this concept being accepted, it is rarely considered in transportation policymaking.

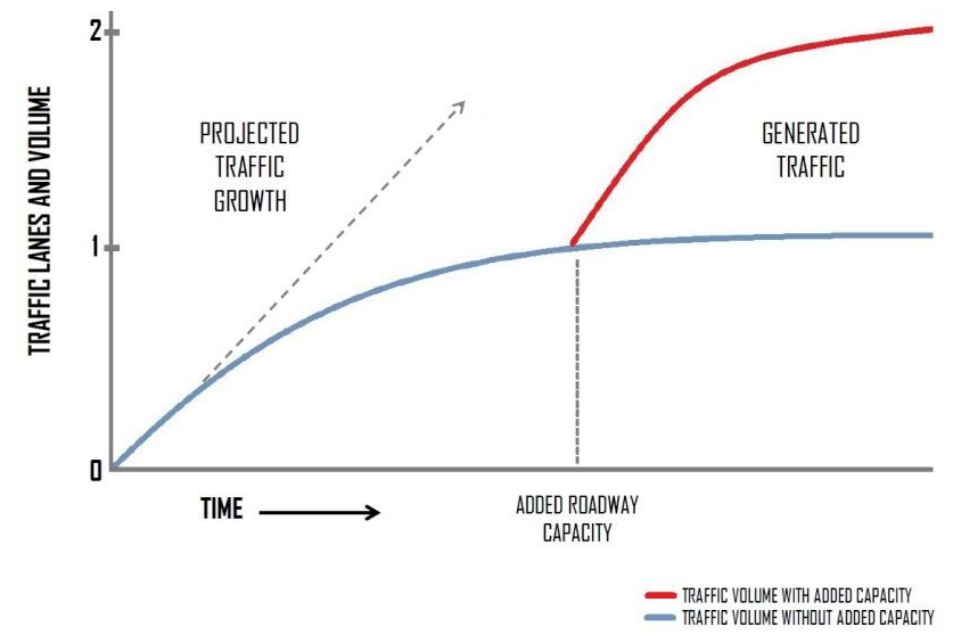

Figure 1: How Road Capacity Expansion Generates Traffic (Source: Litman, 2017).

The purpose of this paper is to investigate the impact of lane closures for construction purposes on congestion and travel reliability, and to evaluate the extent to which these policy actions impact system performance. This is illustrated through a case study of two separate lane closure interventions on the Gardiner Expressway in Toronto, Ontario. Although there is extensive research on induced demand effects, little is known about how and when reduced demand manifests following a deliberate capacity restriction, and to what extent congestion and travel reliability on a major highway is impacted. This study uses big data, in the form of link-based probe data, with before-after methods of analysis. Models using a regression framework are developed for the pre-, peri-, and post-closure test periods of the first intervention, and pre- and peri-closure test periods of the second intervention. Synthetic months are created to distinguish the instance of capacity constraints, average speed is used as a measure of traffic congestion, and travel reliability is assessed by the buffer time index. 


\section{CHAPTER 2: Literature Review}

\section{Induced Demand Effects}

In order for policymakers to be equipped with the knowledge necessary to rationalize road development and capacity expansions, the effects of induced demand need to be understood. Induced demand is reflected in the economic theory of supply and demand and is prevalent in transportation systems, whereby new traffic is attracted by an increase in road capacity and the materialization of latent demand (Downs, 1962; Goodwin, 1996). Latent demand is existing demand that has been suppressed and has not manifested into usage due to existing system incapacity (Vanderbilt, 2008). Therefore, if capacity is increased, latent demand weakens in the short-term as it transforms into tangible system usage. As a result, congestion maintains equilibrium, as "traffic volumes increase to the point that congestion... limits further traffic growth" (Litman, 2017; 3). Much empirical transportation research has documented demand responses to system capacity changes; yet, a consensus on what this means for policymaking has not been achieved (Cervero, 2002). Research on induced demand effects is reviewed below to provide context to this study and identify if a reduction in highway capacity has the potential to reduce congestion and improve system performance in the long-term. It has been established that induced demand varies by region, demographics, and road type, whereby metropolitan highways experience stronger effects than those in rural areas (Hanson \& Huang, 1997). Importantly, induced demand has potential induced-growth and investment effects, and is not strictly a roadway building phenomenon (Cervero, 2002). These effects are particularly prevalent in public transit and traffic operational improvements, such as in the intensification of land uses near transit stations. Thus, induced demand may be interpreted as an indicator that transportation services are valued in new ways by additional users. On the other hand, it can be contended that induced demand undermines the purposes of transportation policies to alleviate congestion or reduce the environmental consequences of automobility.

To understand induced demand, one must be familiar with its first observation. In the 1930s, the incidence of traffic generation was experienced in the highway-building program of Robert Moses in New York. Constructing and widening roads did not alleviate congestion; rather, it aggravated it. The Triborough Bridge was opened to ease congestion on the Queensborough Bridge; however, usage continued to increase. As a result, the Bronx-Whitestone Bridge was opened in an attempt, once again, to disperse traffic. Nevertheless, all three bridges rapidly became traffic clogged. The same phenomenon was observed with the opening of the Queens-Midtown, East River, and Brooklyn-Battery tunnels. As a result of induced demand, congestion continued to increase despite new road infrastructure projects intended to alleviate it (Caro, 1974). Since a new route may be more convenient than the old, resulting in automobile trips from those who otherwise may have chosen not to travel, traffic is generated (Leeming, 1969). The result is an endless spiral involving the construction of new road infrastructure intended to alleviate congestion, with the caveat of increasing travel demand. 
The size of the induced demand effect has been calculated in several studies using econometric techniques. When considering additions to the state highway system in California, Hanson and Huang (1997) identified an elasticity of vehicle-miles traveled (VMT) with respect to lane-miles of 0.6 to 0.7 at the county level, and up to 0.9 at the metropolitan level. Likewise, the Federal Highway Association (FWHA) uses short- and long-term elasticities of -0.27 to -0.57 for urban roads, and -0.67 to -1.33 for rural roads (Goodwin, 1996). In addition, Hanson and Huang (1997) estimated that the full impact of VMT materializes within 5 years of a capacity change, and for every 2-3\% increase in highway lane-miles, there would be an increase of $1 \%$ in total vehicle travel (Hanson \& Huang, 1997; Litman, 2017). Models were estimated using two cross-sectional time series (panels) of area-level data, comprised of observations from 1973 to 1990. It was concluded that adding road capacity would not significantly decrease congestion in the long-term due to induced demand effects (Hanson \& Huang, 1997). Mokhtarian, Samaniego, Shumway, and Willits (2002) used the same data as Hanson and Huang (1997) but conducted a different study. Mokhtarian et al. (2002) applied a matched-pairs technique wherein vehicle trips - rather than vehicle miles - were the dependent variable. A near zero elasticity for vehicle trips with respect to lane-miles was determined, indicating that vehicle trips did not show significant variation despite changes to lane-miles (Mokhtarian et al., 2002).

Fulton, Noland, Meszler and Thomas (2000) estimated an elasticity of VMT with respect to lanemiles on the order of 0.2 to 0.6 . The study modeled VMT as a function of lane-miles at the county level for mid-Atlantic areas in the US. Using a Granger Causality test, it was determined that growth in lane-miles precedes that in VMT (Fulton et al., 2000). Like Hanson and Huang (1997) and Fulton et al. (2000), Noland (2001) supported the hypothesis that added lane mileage induces demand. Specifically, Noland (2001) estimated that $25 \%$ of VMT growth is due to lane-mile additions, and that elasticities are greater in models where data is disaggregated by road type (interstates, arterials, collectors). Panel data of 50 US states between the years 1984 and 1996 was used, and it was found that collectors in urban areas have the largest VMT elasticities on average. Short and long-run elasticities of VMT were determined to be 0.13 and 0.41, respectively (Noland, 2001). Using a similar approach, Hymel, Small, \& Dender (2010) estimated a long-term VMT elasticity of 0.16 , and concluded that congestion most strongly affects demand for driving in higher income areas.

A study by Cervero and Hanson (2000) found the elasticity of VMT with respect to lane-miles to be 0.56 , and the elasticity of lane-miles with respect to VMT to be 0.33 (Cervero \& Hanson, 2000). As such, traffic growth is a result of roadway capacity expansion (Cervero \& Hanson, 2000; Litman, 2017). In another study, Cervero (2003) used data collected between 1980 and 1994 on 24 California highway projects to assess a long-term VMT elasticity, with respect to traffic speed, of 0.64 . Thus, an increase of $10 \%$ in average travel speed would result in a 6.4\% increase in VMT (Cervero, 2003; Litman, 2017).

Several studies have conducted a meta-analysis of induced travel research which identified short and long-term elasticities of VMT with respect to lane-miles. Schiffer, Steinvorth, and Milam's (2005) study 
resulted in the production of Figure 2, which summarizes estimates from 13 authors. The meta-analysis studies (Schiffer et al., 2005; Kockelman, 2010; Handy \& Boarnet, 2014; Litman, 2017) suggest shortterm induced demand effects between 0.0 to 0.6 , and long-term effects between 0.5 to 1.0. Hence, a $10 \%$ increase in lane-miles could potentially result in a $6 \%$ increase in VMT in the short-term and up to a $10 \%$ increase in the long-term. In short, adding new capacity to existing limited access highways is unlikely to reduce congestion in the long-run (Litman, 2017).

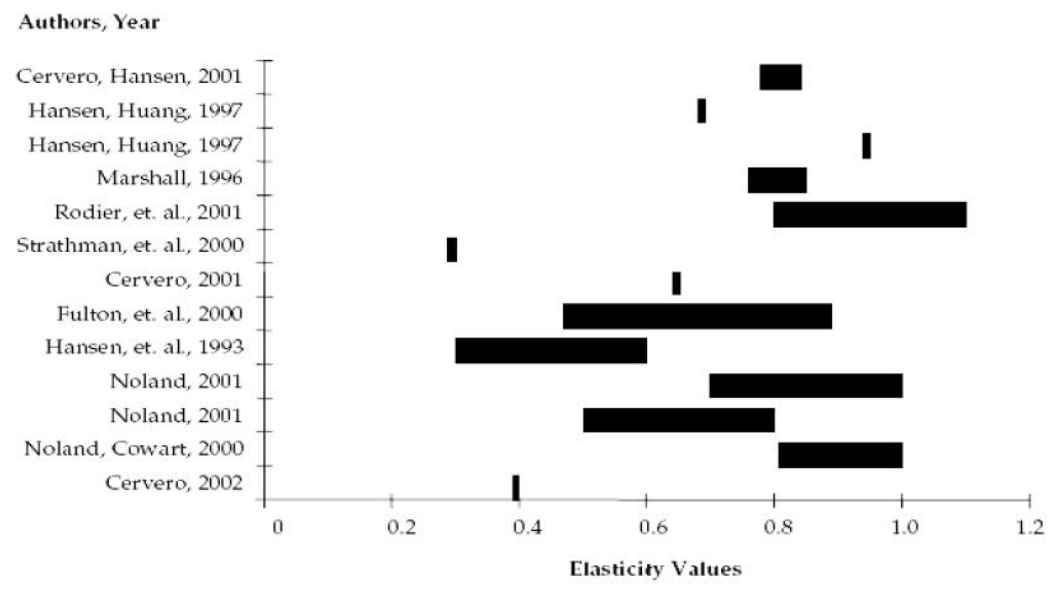

Figure 2: VMT with Respect to Road Capacity (Source: Schiffer et al., 2005).

The Texas Transportation Institute's analysis of the relationship between highway expansion and congestion examined 70 metropolitan areas over a 15 year period, and determined that areas which had heavily invested in road capacity expansions fared no better in alleviating congestion than those who did not make investments (STPP, 1998). The California Association of Governments has even gone so far to conclude that steps taken to alleviate congestion have nothing but a "cosmetic effect" on the problem (Duany, Plater-Zyberk, and Speck, 2000). Likewise, Duranton and Turner (2011) suggested that traffic congestion cannot be fought through road capacity expansions and public transit extensions. Instead, congestion pricing is the "main candidate tool to curb traffic" (Duranton \& Turner, 2011; 35). City level traffic across the US between 1983 and 2003 was analyzed. VKT increased one for one with highways in urban areas, as estimates for elasticity of VKT were 0.86 in OLS and 1.0 in first difference. Duranton and Turner's (2012) research confirmed Anthony Downs' (1962; 1992) 'fundamental law of highway congestion' in that a proportional increase in traffic is expected where an interstate highway is extended.

In all, prior literature provides overwhelming evidence of induced demand effects and a strong positive relationship between urban highway expansion and vehicle travel. Short and long-run elasticities of VMT with respect to lane-miles vary by road type, region, and demographics. When capacity changes are implemented, a wide spectrum of effects can result as estimated elasticities range from 0.0 to 1.0. If you build it, they will come, as adding capacity induces more travel demand. Therefore, congestion cannot be improved through conventional traffic alleviating measures such as adding lanes. Instead, it must be combated through congestion pricing. 


\section{Reduced Demand Effects}

When capacity is deliberately restricted such as in reducing the number of available lanes for road maintenance purposes, short-term congestion increases. Yet, in the long-term there is a reduction in travel demand and a subsequent decrease in congestion. Disappearing traffic, traffic evaporation, and traffic suppression are indicators of reduced demand - the inverse effect of induced demand. By decreasing road capacity, the cost of travel immediately increases at travel times lengthen, leading to a reduction in demand for road usage (Vanderbilt, 2008). Increased costs can lead to an adjustments in traveler behaviour. For instance, a new mode of transport may be used, and trips may be retimed, occur less frequently, or be abandoned all together.

There are far fewer studies examining reduced demand effects, especially in relation to highway capacity. The West Side Highway in New York is the most widely known example of the reduced demand phenomena. Following the collapse of several sections of the lower portion of the highway in 1973, large segments were torn down rather than rehabilitated. Over 80,000 motorists used the highway each day and now needed to find alternative routes to their destinations. Newly displaced traffic from the highway was expected to cause chaos by clogging local streets. Yet, this did not occur; instead, the traffic disappeared (Speck, 2012; Schwartz, 2015). The highway had induced the demand for car travel, and with its removal fewer trips were made by automobiles, thereby reducing traffic. According to the New York State Department of Transportation, 93\% of the traffic which had used the highway vanished, leading to insignificant increases in local road congestion following the highways demolition (Duany et al., 2000). This same effect has been observed on other highways, including: the Harbor Drive Expressway in Portland, Park East Freeway in Milwaukee, Embarcadero and Central Freeways in San Francisco, and the Cheonggyecheon Freeway in Seoul (Speck, 2012).

Portland was the first city to initiate the idea of full highway demolition, which came to fruition in 1974 when the three-mile long Harbor Drive Expressway was replaced with a 37-acre park. At its peak, the highway carried 25,000 vehicles a day, and was heavily congested. Following the demolition of the highway, 9.6\% fewer vehicle trips were made on nearby roads and formally connected bridges (City of Seattle, 2008). Thus, the surrounding road network was able to successfully accommodate the former highway's traffic. This same success was observed on the Central Freeway of San Francisco. At its peak, the highway serviced over 100,000 vehicles a day. However, following the 1989 earthquake, segments needed to be demolished or closed for extended periods of time for repair. When gridlock failed to materialize on nearby roads as a result of closures, the decision was made to close the expressway for good (City of Seattle, 2008). The Cheonggyecheon Freeway in Seoul was removed in 2005. Over 160,000 vehicles utilized the highway each day, $5 / 8$ s of which was through traffic. When the highway was torn down and converted into a linear park, the number of vehicles downtown decreased by $9 \%$ (City of Seattle, 2008). The above examples are testament to the effects of reduced demand, and proof that a reduction in roadway capacity can reduce congestion in the long-term. 
In another example, the I-35W Bridge over the Mississippi River in Minneapolis collapsed unexpectedly during evening rush hour on August 1'st, 2007. Levinson and Zhu (2010) conducted an analysis of the impact of the collapse on the surrounding road network's traffic flow. Prior to collapse, over 150,000 motorists crossed the eight-lane bridge daily, with average trips taking approximately 18.6 minutes. Post-collapse, Levinson and Zhu (2010) documented that traffic stabilized in about six weeks immediately around the bridge site, and average trip length grew by only two-tenths of a minute. Moreover, due in part to the flexibility of individual travel patterns and network capacity redundancy, peak travel demand remained consistent with that of previous weeks for the system (Levinson \& Zhu, 2010). Levinson and Zhu (2010) described that an avoidance phenomenon was observed following the bridge's collapse, whereby drivers avoided the disruption area until the perceived risk was reduced to an acceptable level with time. This in turn resulted in an oscillation of travel demand around the collapse site, wherein "the scale and longevity of such oscillation diminishe[d] as the area of analysis become larger and the number of meaningful alternative routes increase[d]" (Levinson \& Zhu, 2010; 71). Although psychological shock brought about by the unexpected event is presumed to have discouraged road usage (Levinson \& Zhu, 2010), the I-35W Bridge collapse is an interesting case study for policymakers to explore. Whether or not reduced demand effects or network redundancy limited traffic flow post-collapse remains to be determined.

Today, an increasing number of cities, including Toronto, are considering the possibility of demolishing all or part of their existing downtown highways. New trends in urban planning and sustainability practices, supported by empirical evidence and case studies of the reduced demand phenomenon, are encouraging this movement. Yet, the subject remains underresearched and a contextual gap is present. The effects of reduced demand and the impact of deliberate capacity restrictions on highways, such as lane closures for construction purposes, are uncertain. Literature on how changes in capacity impact system performance and whether or not congestion and travel reliability improve following a prolonged closure needs to be expanded. In completing this research, contextual gaps will be filled as more insight to the effects of induced and reduced demand can be gained, and used to inform Toronto's transportation policies and infrastructure projects moving forward. Research results will have implications as to how to better plan and manage expressways in major cities, as they will evaluate policy actions and determine the extent to which a reduction in capacity can reduce demand and improve performance. 


\section{The Gardiner Expressway and Asset Management Challenges}

The Gardiner Expressway began as a vision by Frederick Gardiner, the first chair of the now-defunct Metro Council, to modernize Toronto's infrastructure with the construction of a "superhighway" that connected the city from the Humber River to Woodbine Ave. Construction began in 1955, with the first section between the Humber and Jameson Ave. completed in 1958, and the interchange to the Don Valley Parkway (DVP) completed in 1966 (Kane, 2014). Today the Gardiner is 18 kilometres in length, running from the Queen Elizabeth Way at Highway 427 to the Don Valley Parkway (Figure 3). The highway averages three lanes in each direction, and is owned and operated by the City of Toronto. Since its inception, the traffic-clogged expressway has been synonymous with congestion. When the first section of the Gardiner opened on August 8th, 1958, there was a traffic jam - attributed to the VIP corteges of dignitaries who attended the ceremony. Three days later the expressway experienced its first accident, resulting from an impaired driver (DiManno, 2012). Today Toronto is ranked the 9th most congested city in North America and 2nd worse for traffic in Canada, with commuters spending an extra $25 \%$ more time traveling on highways as a result of congestion (The Canadian Press, 2016; TomTom, 2016).

Despite the expressway's unreliability, poor performance and daily traffic deadlock, the Gardiner is a major piece of the regional highway system and a key component of Toronto's transportation infrastructure. Recently, Mayor John Tory of the City of Toronto has proposed a road toll of $\$ 2.00$ per trip along the Gardiner (Rieti, 2017). The toll is expected to generate over $\$ 200$ million annually, which would be used to fund highway repairs and transit infrastructure projects. However, the Province, under Premier Kathleen Wynne, blocked the road tolls because the city was viewed to lack "reliable transit options". In addition, the Province denied city council's request for regulatory change which would allow the City to fully manage its own asset (Rieti, 2017). The role of the City as an asset manager of a regionally significant facility is called into question. Had the road tolls been approved, $60 \%$ of revenue was anticipated to be received from Torontonians, while the remaining $40 \%$ would be from residents from other municipalities (Toronto Star, 2016). With over 100,000 vehicles using the Gardiner each day (City of Toronto, 2013), a decision to toll the roads has the potential to significantly affect the travel behaviour of users from across the Greater Toronto Area. Should the decision to toll roads then rest with the City or with the Province? As the region continues to grow and the aging infrastructure begins to crumble, managing and alleviating traffic congestion along the Gardiner to improve system performance becomes increasingly difficult. Between 2013 and 2022, Toronto City Council has pledged to spend over $\$ 500$ million on road rehabilitation work on the Gardiner (City of Toronto, 2016), raising concerns about the impact of lane closures and road restrictions expected to take over six years to construct. Whether or not reducing Gardiner Expressway highway capacity is likely to create or reduce traffic is of interest to city policymakers. 


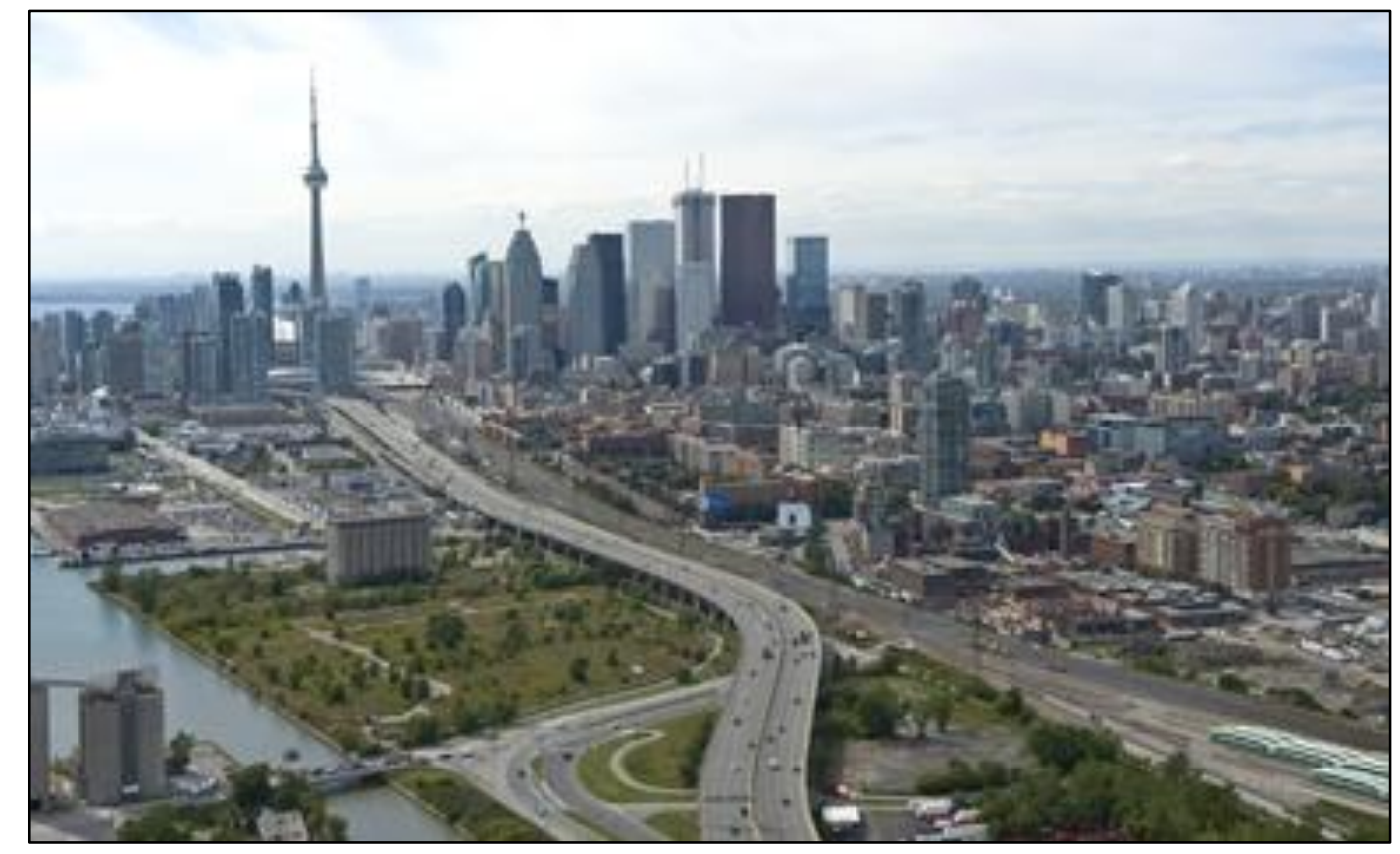

Figure 3: The Gardiner Expressway (Source: City of Toronto, 2016).

\section{Research Overview}

In this study, the Gardiner Expressway is used as a case study in employing before-after methods of analysis using big data to investigate the impact of lane closures on congestion and travel reliability. Trade-offs between performance indicators on a major downtown highway are assessed, and the effectiveness of policy action in improving system performance is evaluated. Particular attention is paid to induced and reduced demand effects. The focus of the study is on two lane closures:

- Intervention 1: April 28, 2014 to April 22, 2015

- Lane closures between Jarvis St. and Park Lawn Ave., one lane each direction

- Intervention 2: August 19, 2015 to June 23, 2016

- Lane closures between Strachan Ave. and Jameson Ave., one lane each direction from August $19^{\text {th }}, 2015$ to November $9^{\text {th }}, 2015$. On November $10^{\text {th }}, 2015$ the previouslyclosed westbound lane reopened.

Models using a difference-in-differences (DID) regression framework were developed for the pre-, peri-, and post-closure test periods of the first intervention, and pre- and peri-closure test period of the second intervention.

The research approach and methodology are adapted from the work of Giuliano, Chakrabarti, and Rhoads (2015), wherein big data and before-after methods of analysis are used to examine latent travel demand and peak-period system performance impacts of a new light rail transit line in Los Angeles, California. 


\section{Before-After Analysis \& Models}

The before-after method is particularly useful as an evaluation tool as the control group pretest-post-test approach measures changes between the 'pretest' and 'post-test' state of variables, for a treated group (referred to as the experimental group) and untreated control group following an intervention. Identical external confounding factors are assumed to be shared between the experimental and control groups, thereby strengthening the assertion that the results of the study were principally due to the treatment effect (Kaatz \& Sweet, 2016).

In this study a control group pretest-post-test method was expanded to explore changes before, during, and after lane closures from April 28th, 2014 to April 22nd, 2015, and before and during lane closures from August 19th, 2015 to June 23rd, 2016 on the Gardiner Expressway. The dates for the intervention pre-, peri-, and post-closure tests are displayed in Table 1. To explore result reliability and sensitivity to different specifications, multiple models were developed with differing experimental and control groups (Table 2).

Table 1: Periods for Intervention Pre-, Peri-, and Post-Closure Tests.

\begin{tabular}{|c|c|c|c|}
\hline Intervention & Before (Pre-Closure) & During (Peri-Closure) & After (Post-Closure) \\
\hline \multirow{2}{*}{1} & $\begin{array}{c}\text { January 1st, 2014 to } \\
\text { April 27th, 2014 }\end{array}$ & $\begin{array}{c}\text { April 28th, 2014 to } \\
\text { April 21st, 2015 }\end{array}$ & $\begin{array}{c}\text { April 22nd, 2015 to } \\
\text { August 18th, 2015 }\end{array}$ \\
\hline \multirow{2}{*}{$\mathbf{2}$} & $\begin{array}{c}\text { April 22nd, 2015 to } \\
\text { August 18th, 2015 }\end{array}$ & $\begin{array}{c}\text { August 19th, 2015 to } \\
\text { June 23rd, 2016 }\end{array}$ & \\
\hline
\end{tabular}

During both intervention periods, lane closures were continuous (all-day). Between the end of Intervention 1 and beginning of Intervention 2, all lanes in the eastbound and westbound directions were reopened for the Toronto 2015 Pan-Am Games (July 10th $-16^{\text {th }}$ ) and Parapan-Am Games (August $7^{\text {th }}-$ $\left.15^{\text {th }}\right)$. To help athletes, officials, visitors, and residents move through the city and arrive at venues, one lane in each direction of the Gardiner between Spadina Avenue and the QEW were temporarily converted to High Occupancy Vehicle (HOV) lanes. From June $29^{\text {th }}$ to July $27^{\text {th }}$, HOV $3+$ lanes were enforced (5am $11 \mathrm{pm})$. From July $28^{\text {th }}$ to August $18^{\text {th }}, 2015$, HOV $2+$ lanes were in effect (5am $-11 \mathrm{pm}$ ).

Table 2: Experimental and Control Groups for Models.

\begin{tabular}{|c|c|c|c|}
\hline No. & Intervention & Experimental Group & Control Group \\
\hline 1 & $1 \& 2$ & Treated Links of Gardiner Expressway & Highway 401 Links \\
\hline 2 & $1 \& 2$ & Treated Links of Gardiner Expressway & $\begin{array}{c}\text { Untreated Links of Gardiner Expressway } \\
\text { and Highway 401 Links }\end{array}$ \\
\hline 3 & 2 & Gardiner Expressway Links & Highway 401 Links \\
\hline
\end{tabular}




\section{Measures}

To estimate the effects of lane closures on recurring congestion and travel reliability on the Gardiner Expressway, models using a regression framework were developed for the pre-, peri-, and/or post-closure test periods of each intervention (Table 1). Policy actions (lane closures) were tested on speed (measure of traffic congestion) and the buffer time index (unreliability measure). The buffer time index (BTI) begins at 1.0 and represents the ratio of the 95th percentile slowest travel times to the mean travel times. Hence, the buffer time index compares the most extreme travel times (95 ${ }^{\text {th }}$ percentile slowest) with those which are typical. Higher average travel speeds are symptomatic to less congestion, and a lower buffer time index indicates more reliable conditions. To conduct the before-after analysis, synthetic months and a binary "treated" variable were created to be used as factors in the models and ease result interpretability.

\section{Synthetic Months}

To conduct the before-after analysis, synthetic months were created to represent whether the lane reduction was in place or had not yet been implemented. Each intervention has a unique calendar, wherein the first day of Month 1 is the start date of the lane closure. Each month has approximately 30 days, with the only exceptions being: 29 days in Months 12 and 16 for Intervention 1 and Month -3 for Intervention 2, and 10 days in Month 11 for Intervention 2. To avoid noise, the analysis period for Intervention 1 ended a day prior to the start of the pre-closure period of Intervention 2. Likewise, the analysis period establishing the benchmark before Intervention 2 begins the day the Gardiner lanes reopened following Intervention 1. In this report, the "month.a" variable refers to the synthetic months of Intervention 1's calendar, and "month.b" refers to those of Intervention 2 (Table 3). These notations are used in figures and the report's discussion.

\section{Speed and Reliability}

This study uses probe road speed data from Inrix Inc., wherein Traffic Message Channel (TMC) links are the units of observation (Figure 4). TMCs are unique to a section of road within a network and vary in length. The Gardiner Expressway is comprised of 51 links, ranging from 0.007 to 1.801 miles. Linkspecific speed data in 15-minutes intervals for each hour, day, and month of the year was aggregated to unique hours of the day (5am to 9pm), on typical weekdays (Monday to Friday), for each synthetic month of the year. In doing so, sufficient variation in congestion (average speed) and travel reliability (buffer time index) estimates for analysis could be provided. In addition, the free-flow speed (the 95th percentile fastest speed) of each TMC link was calculated from the speed data and used as a factor in the models 
Table 3: Synthetic Month Calendars.

\begin{tabular}{|c|c|c|c|c|}
\hline & \multicolumn{2}{|c|}{$\begin{array}{c}\text { Intervention 1: } \\
\text { April 28, } 2014 \text { to April 22, } 2015\end{array}$} & \multicolumn{2}{|c|}{$\begin{array}{c}\text { Intervention 2: } \\
\text { August } 19,2015 \text { to June } 23,2016\end{array}$} \\
\hline $\begin{array}{c}\text { Synthetic } \\
\text { Month }\end{array}$ & First Day & Last Day & First Day & Last Day \\
\hline-3 & December 29, 2013 & January 27, 2014 & April 22, 2015 & May 20, 2015 \\
\hline-2 & January 28, 2014 & February 26, 2014 & May 21,2015 & June 19, 2015 \\
\hline-1 & February 27, 2014 & March 28, 2014 & June 20, 2015 & July 19, 2015 \\
\hline 0 & March 29, 2014 & April 27, 2014 & July 20, 2015 & August 18, 2015 \\
\hline 1 & April 28, 2014 & May 27, 2014 & August 19, 2015 & $\begin{array}{l}\text { September 17, } \\
2015\end{array}$ \\
\hline 2 & May 28, 2014 & June 26, 2014 & $\begin{array}{l}\text { September 18, } \\
2015\end{array}$ & October 17, 2015 \\
\hline 3 & June 27, 2014 & July 26, 2014 & October 18, 2015 & November 16, 2015 \\
\hline 4 & July 27,2014 & August 25, 2014 & November 17, 2015 & December 16, 2015 \\
\hline 5 & August 26, 2014 & $\begin{array}{l}\text { September 24, } \\
2014\end{array}$ & December 17, 2015 & January 15, 2016 \\
\hline 6 & $\begin{array}{l}\text { September 25, } \\
2014\end{array}$ & October 24, 2014 & January 16, 2016 & February 14, 2016 \\
\hline 7 & October 25, 2014 & November 23, 2014 & February 15, 2016 & March 15, 2016 \\
\hline 8 & November 24, 2014 & December 23, 2014 & March 16, 2016 & April 14, 2016 \\
\hline 9 & December 24, 2014 & January 22, 2015 & April 15, 2016 & May 14, 2016 \\
\hline 10 & January 23, 2015 & February 21, 2015 & May 15,2016 & June 13, 2016 \\
\hline 11 & February 22, 2015 & March 23, 2015 & June 14, 2016 & June 23, 2016 \\
\hline 12 & March 24, 2015 & April 21, 2015 & & \\
\hline 13 & April 22, 2015 & May 21, 2015 & & \\
\hline 14 & May 22,2015 & June 20, 2015 & & \\
\hline 15 & June 21, 2015 & July 20, 2015 & & \\
\hline 16 & July 21, 2015 & August 18, 2015 & & \\
\hline
\end{tabular}




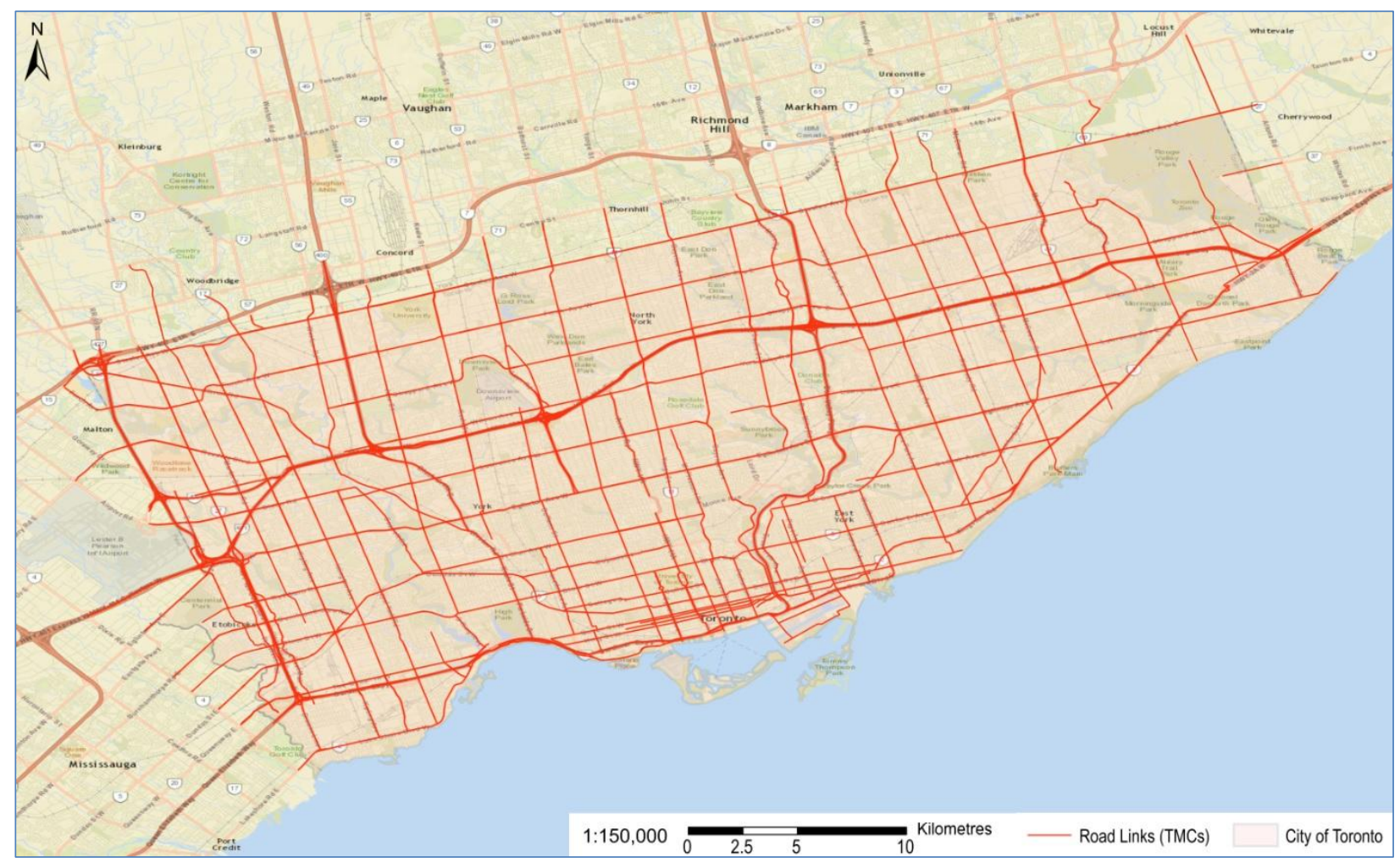

Figure 4: Traffic Message Channels (TMCs).

\section{Treated}

To indicate if a TMC was within the capacity reduction zone and received treatment, the "treated" binary measure was created. If a TMC, or any portion thereof, fell within the lane reduction area it was assigned a value of 1 . TMCs outside of the zone in their entirety received a 0. Figure 5 displays the Gardiner Expressway's treated and untreated sections of the first intervention, and Figure 6 displays those of the second. In the models, the treated variable was used to distinguish the experimental group from the control group (Table 2). Due to a relatively low number of observations available, TMCs were not further subdivided by direction for analysis in this study. However, a directionality-specific analysis of treated and untreated TMC links was completed in the Gardiner Expressway Performance, Safety, and Reliability study within the Before-After Methods: Transportation Policy and Performance in Toronto report. 
Intervention 1: April 28, 2014 to April 22, 2015

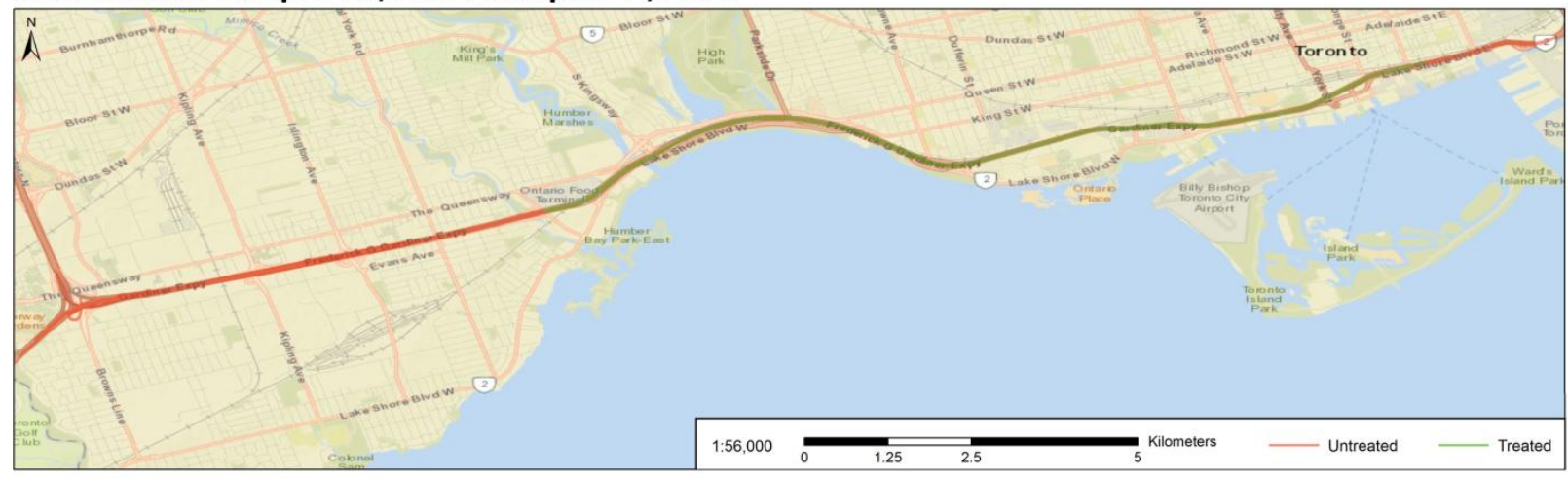

Figure 5: Intervention 1: Gardiner Expressway Treated and Untreated Sections.

Intervention 2: August 19, 2015 to June 23, 2016

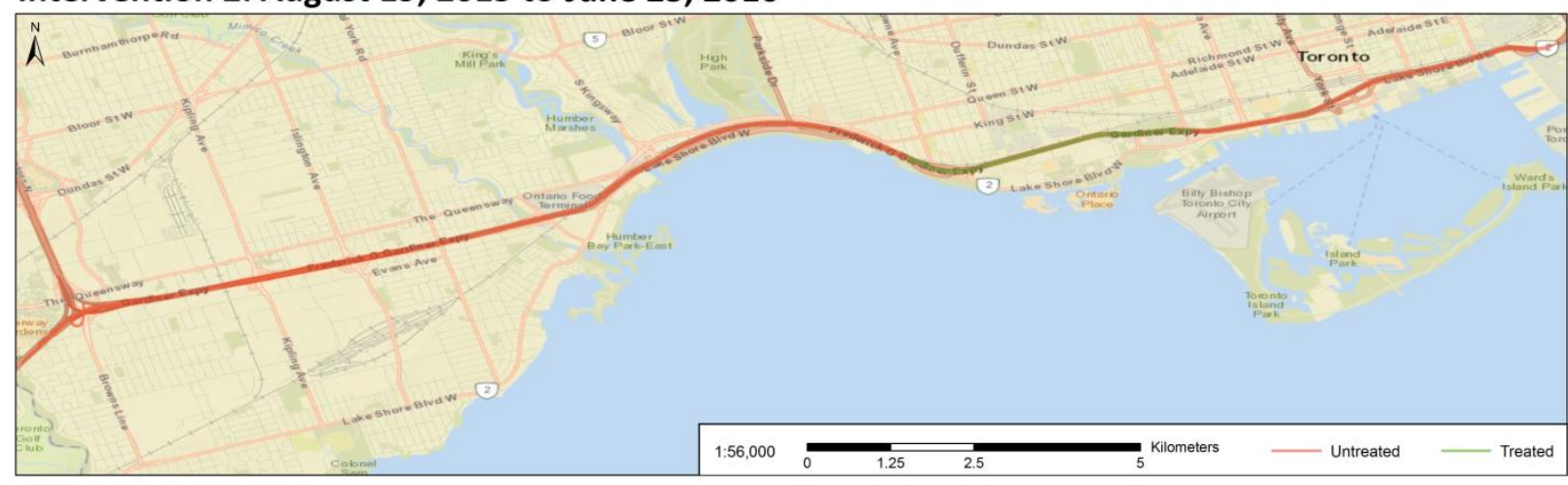

Figure 6: Intervention 2: Gardiner Expressway Treated and Untreated Sections.

\section{Lane Closure Boundaries}

Matching TMCs to intervention boundaries was done as best possible, but an imperfect geographic relationship exists between treatment areas and TMC spans. For instance, in Intervention 2 the lane closures occurred between Strachan Avenue and Jameson Avenue, a distance of approximately 2.0 kilometres. Yet, the 4 TMC links representing the treatment area extend over 3.0 kilometres, from near Dowling Avenue to Bathurst Street, due to varying link lengths (see Figure 6). As previously mentioned, TMCs were identified as "treated" if any portion of the link fell within the lane reduction area. As a result, treated sections overlap with untreated sections in reality, and the relative differences in congestion and travel reliability between experimental and control groups of the models may be understated.

\section{Modeling Approach}

For the pre-, peri-, and/or post-closure test periods of each intervention (Table 1), two aspects of system performance - speed and travel reliability - are examined for the weekday $5 \mathrm{am}$ to $9 \mathrm{pm}$, peak-AM (6am to $10 \mathrm{am}$ ), and peak-PM (3pm to $7 \mathrm{pm}$ ) periods. Due to unknown external factors, a simple comparison of differences in means for the experimental group before and after each intervention may be misleading, 
as changes cannot be exclusively attributed to the lane closures. Likewise, a post-lane closure comparison between the experimental and control groups' performance measures may be subject to certain biases due to innate differences between the groups (Giuliano et al., 2015). Hence, a simpler approach is not sufficient to evaluate the impacts of the lane closures, and a difference-in-differences (DID) regression analysis is adopted.

Through a DID regression analysis, the effect of a treatment (lane closures) on a response variable (congestion or travel reliability) is calculated by comparing average changes between an experimental and control group at two or more different time periods. The experimental group is assumed to have been exposed to a treatment in the peri- and post-closure period, while the control group is assumed to have not received treatment. External factors are understood to equally influence both groups, as "the effect of regional traffic trends on experimental and control segments of the freeway corridor are expected to be similar by design. Since the same parameters (outcomes) within both groups are observed in [each] time period, the average gain in the control group is subtracted from the average gain in the experimental group" (Giuliano et al., 2015; 203). To conduct the DID regression analysis, synthetic months and the treated variable are used to indicate the time when treatment started and to identify the group exposed to the treatment. Congestion and travel reliability outcomes are each estimated independently using multiple linear regression models, weighted by TMC length. For congestion models, average vehicle speed is the response variable with the following as explanatory variables: freeflow speed, treated, synthetic months, the interaction between treated and synthetic months, the time period (either $5 \mathrm{am}$ to $9 \mathrm{pm}$, peak-AM, or peak-PM), and TMC link. For travel reliability models, the buffer time index is the response variable, with average vehicle speed, treated, synthetic months, the interaction between treated and synthetic months, the time period (either 5am to 9pm, peak-AM, or peak-PM), and TMC links as factors. Regression analysis is used rather than more simplified testing, such as ANOVA, due to continuous independent variables and uncertainty in whether or not the independent categorical variables have any effect (Barnes, 2012).

Coefficient estimations from the DID regression analysis for congestion and travel reliability models reveal the impact of lane closures on system performance measures. The regression analysis uses control group conditions for synthetic Month -3 as reference for all models. As such, the coefficient estimations for the synthetic months are indicative of background trends and reveal seasonality effects, and the coefficients of the interaction effects quantify the impact of lane closures. For instance in an Intervention 1 congestion model, a coefficient of -0.28 for the interaction effect of synthetic Month 1 to treated may be observed. This would indicate that average speeds dropped by nearly $30 \%$ during the first month of the lane closure period, with regards to control conditions three months prior to the start of the intervention. In examining changes in the coefficients pre-, peri-, and post-closure, the impact of policy interventions on system performance can be observed. 


\section{CHAPTER 4: DATA OVERVIEW}

Before conducting the before-after analysis of the impact of lane closures on congestion and travel reliability, descriptive statistics were compiled to gain more insight to the dataset and identify changes in system performance between January 2014 and June 2016.

\section{Gardiner Expressway vs. Highway 401 vs. City of Toronto Highways}

The Gardiner Expressway is comprised of 51 direction-specific links (TMCs). City of Toronto highways, including the Gardiner, QEW, DVP, and Highways 400, 401, 404, 407, 409, and 427, have a total of 411 links. The section of Highway 401 bounded by Highway 427 and the DVP (hereafter referred to as “Highway 401") consists of 106 TMCs. Congestion and travel reliability data was aggregated to unique hours of the day (5am to 9pm), on typical weekdays, for each month of the year. Significant differences between the monthly and hourly speed and buffer time index profiles are observed, with the Gardiner Expressway performing below average on most accounts (Figures 7-12).

In the month following the start of a lane closure, the Gardiner, Highway 401, and City of Toronto highways all experience notable reductions in average travel speeds and increases in travel unreliability (April 2014 and August 2015). This finding may suggest that a significant number of Gardiner Expressway commuters altered their routes during the lane closure period in an attempt to avoid the expected, increased congestion on the Gardiner, resulting from capacity reductions. As such, the policy interventions on the Gardiner do not appear to have been isolated as they impact the system. The slowest speeds and most unreliable conditions were observed during peak travel time hours (e.g. 8am and 5pm).

Following the end of the first intervention in April 2015, average speeds immediately increased on the Gardiner, but congestion levels remained steady on Highway 401 and City of Toronto highways. As a result of the Toronto 2015 Pan-Am Games (July 10th $-16^{\text {th }}$ ) and Parapan-Am Games (August $7^{\text {th }}-15^{\text {th }}$ ), all assets experienced significant increases in congestion and unreliability during the summer of 2015.

From 2014 to 2016, the average speed on the Gardiner Expressway was $51.1 \mathrm{mph}$ approximately $4.0 \mathrm{mph}$ slower than City of Toronto highways and $0.75 \mathrm{mph}$ slower than Highway 401 . The average buffer time index was 1.57 - lower than the City of Toronto highway average by 0.07, but better than the Highway 401 average by 0.10. Year-to-year differences exist (Table 4), with 2014 being the most congested and unreliable for the Gardiner Expressway. In the three year period, City of Toronto highways have improved in regards to reliability, while Highway 401 has worsened. In looking at these statistics as a whole, it has been established that differences between the performance of the Gardiner Expressway and Highway 401 are minor. As such, Highway 401 is a suitable control for the Gardiner in the analysis. 
Table 4: Average Speeds (mph) and BTIs: Monday to Friday, 5AM - 9PM.

\begin{tabular}{|c|c|c|c|c|c|c|}
\hline \multirow{2}{*}{} & \multicolumn{2}{|c|}{2014} & \multicolumn{2}{c|}{2015} & \multicolumn{2}{c|}{2016} \\
\cline { 2 - 7 } & Speed & BTI & Speed & BTI & Speed & BTI \\
\hline $\begin{array}{c}\text { Gardiner } \\
\text { Expressway }\end{array}$ & 50.84 & 1.60 & 51.18 & 1.56 & 51.30 & 1.54 \\
\hline $\begin{array}{c}\text { City of Toronto } \\
\text { Highways }\end{array}$ & 55.95 & 1.51 & 54.49 & 1.50 & 54.67 & 1.49 \\
\hline Highway 401 & 52.56 & 1.67 & 51.26 & 1.67 & 51.42 & 1.69 \\
\hline
\end{tabular}




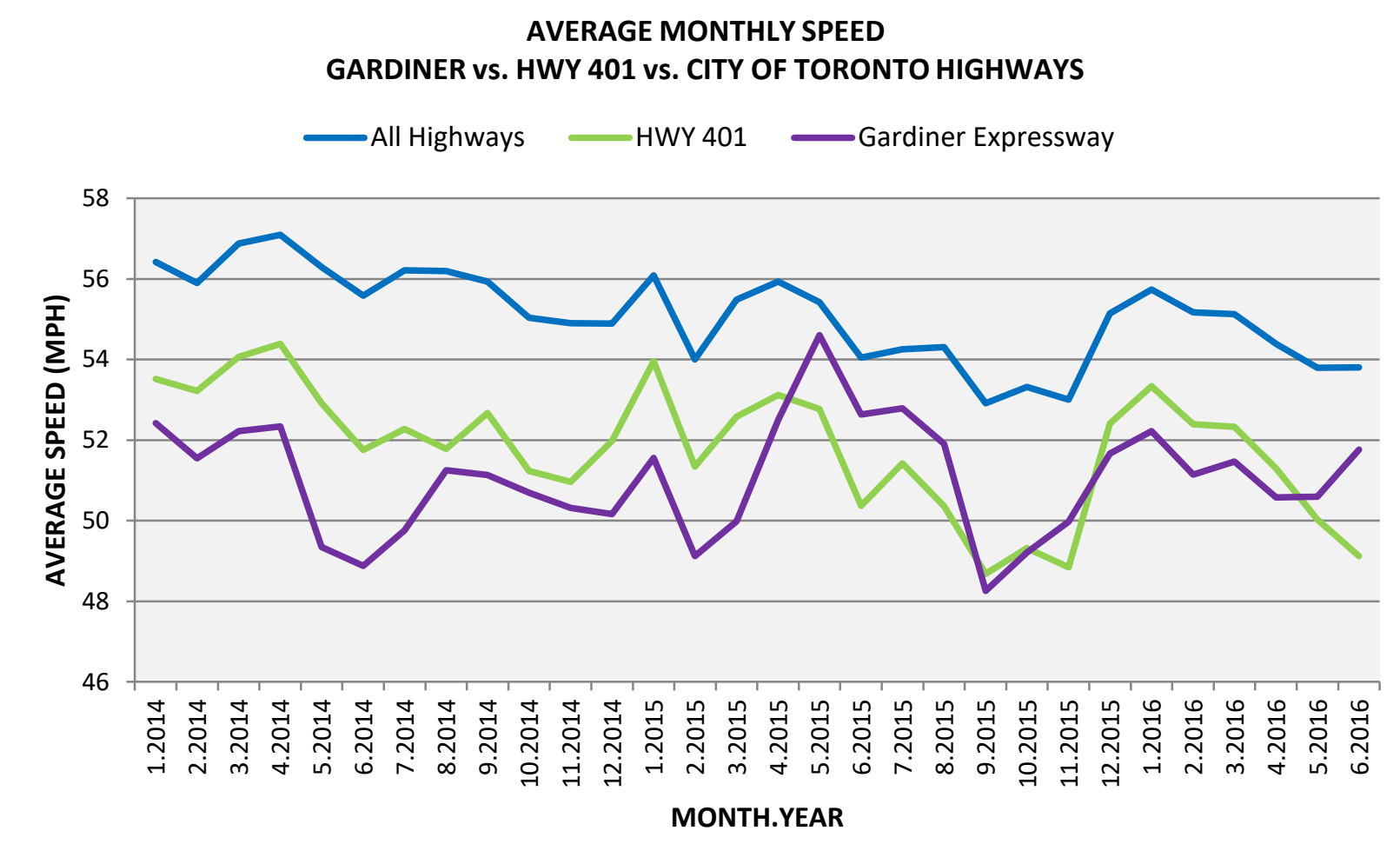

Figure 7: Average Monthly Speed: Gardiner vs. Highway 401 vs. City of Toronto Highways.

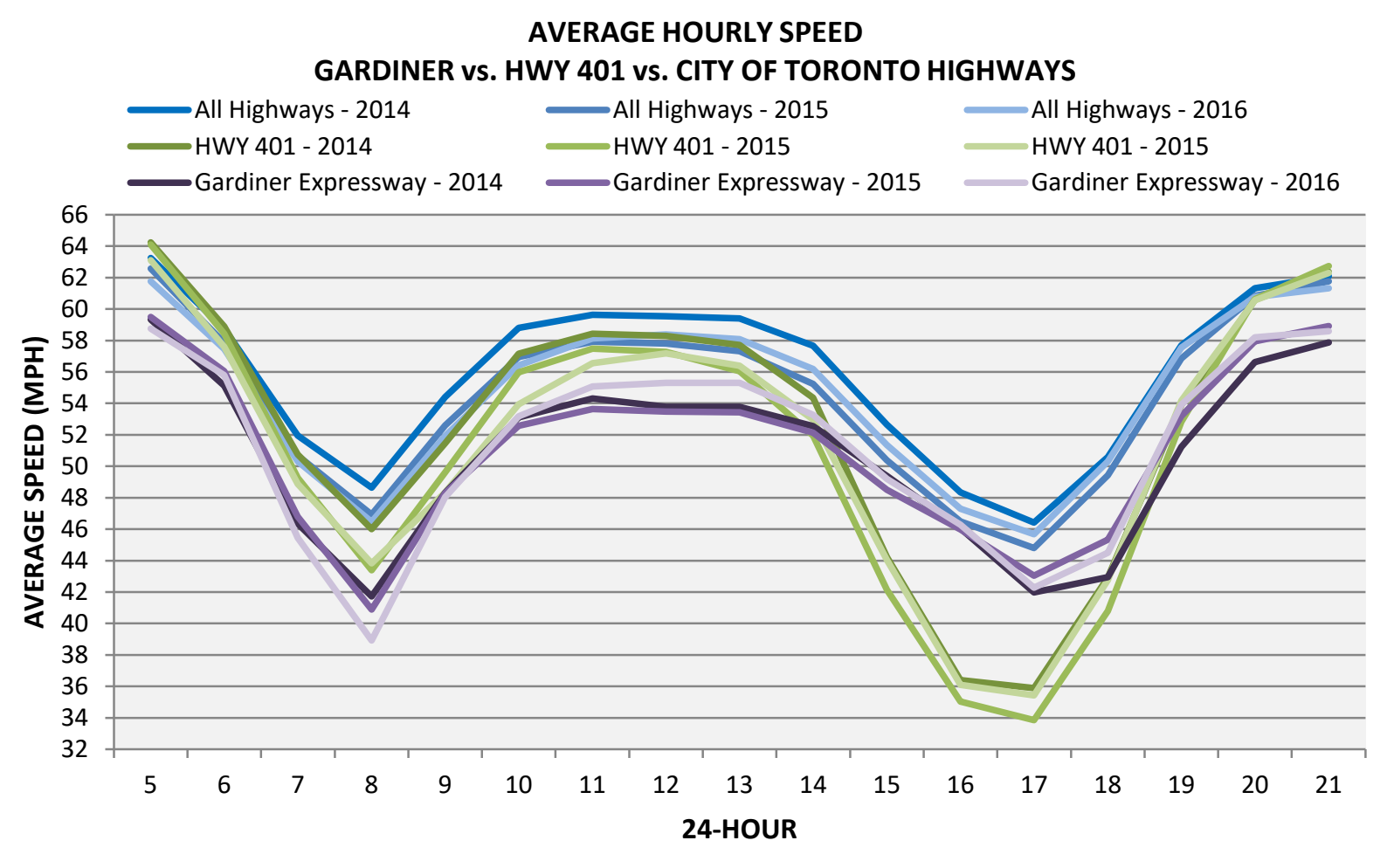

Figure 8: Average Hourly Speed: Gardiner vs. Highway 401 vs. City of Toronto Highways. 


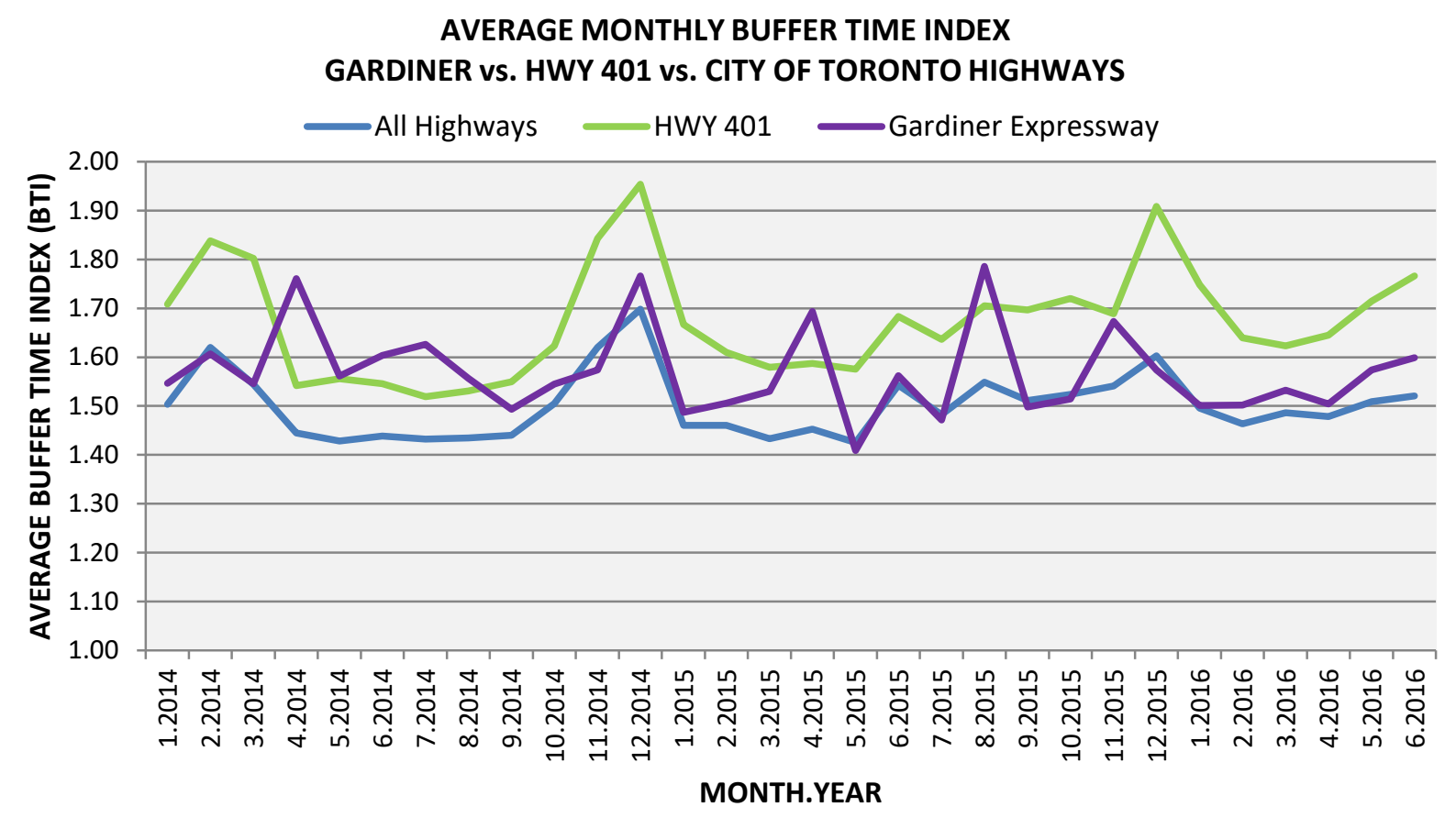

Figure 9: Average Monthly BTI: Gardiner vs. Highway 401 vs. City of Toronto Highways.

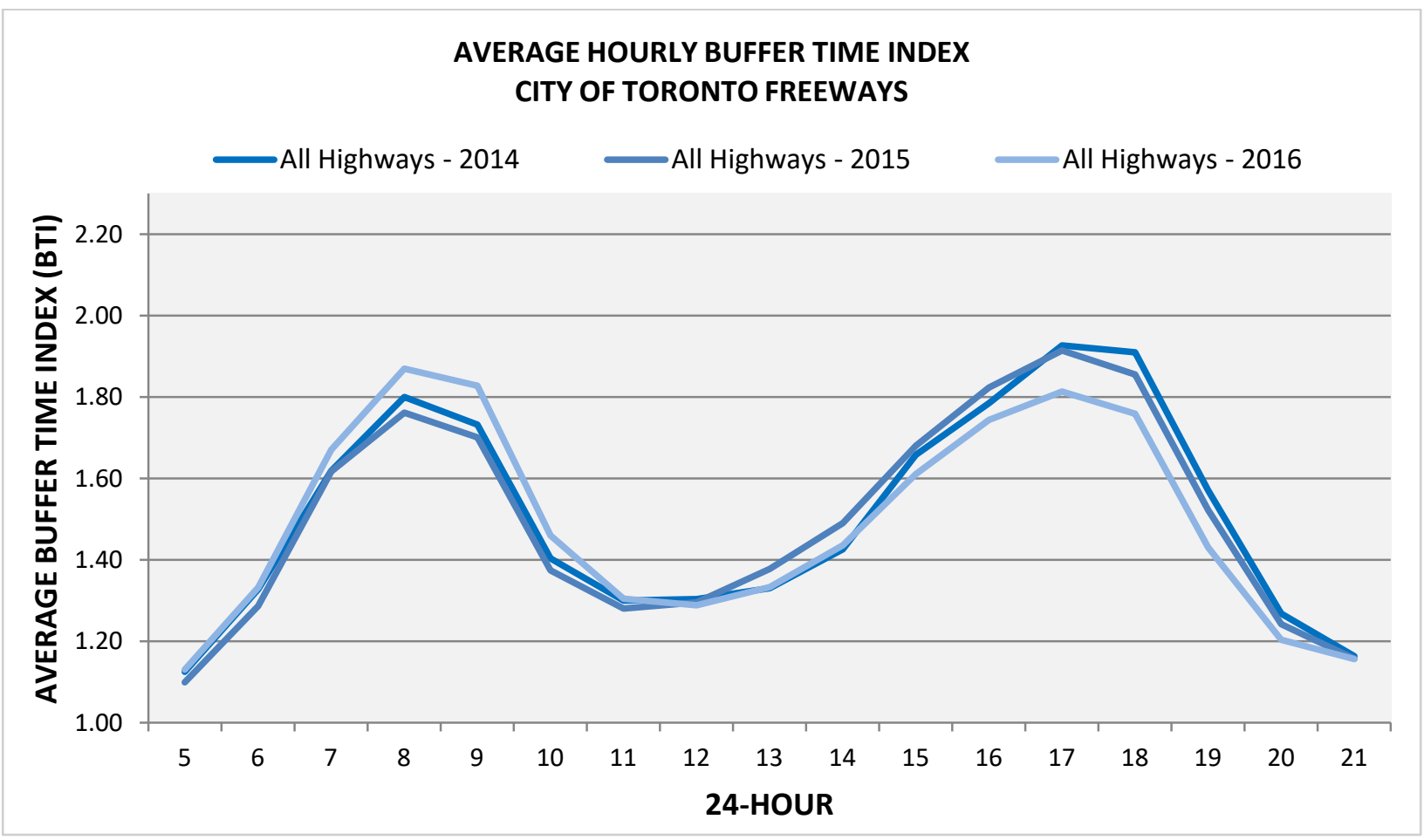

Figure 10: Average Hourly BTI: City of Toronto Highways, 2014-2016. 


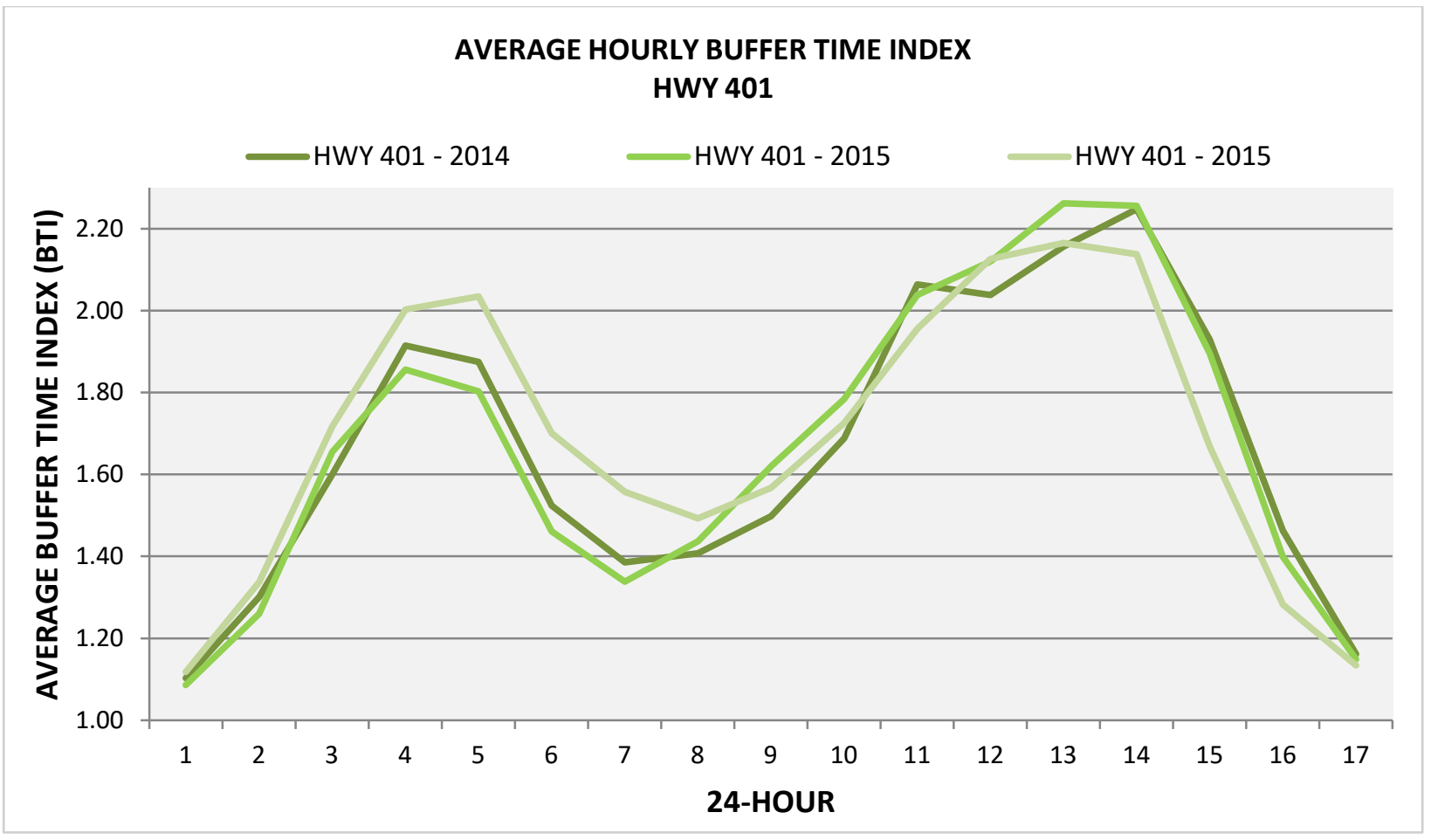

Figure 11: Average Hourly BTI: Highway 401, 2014-2016.

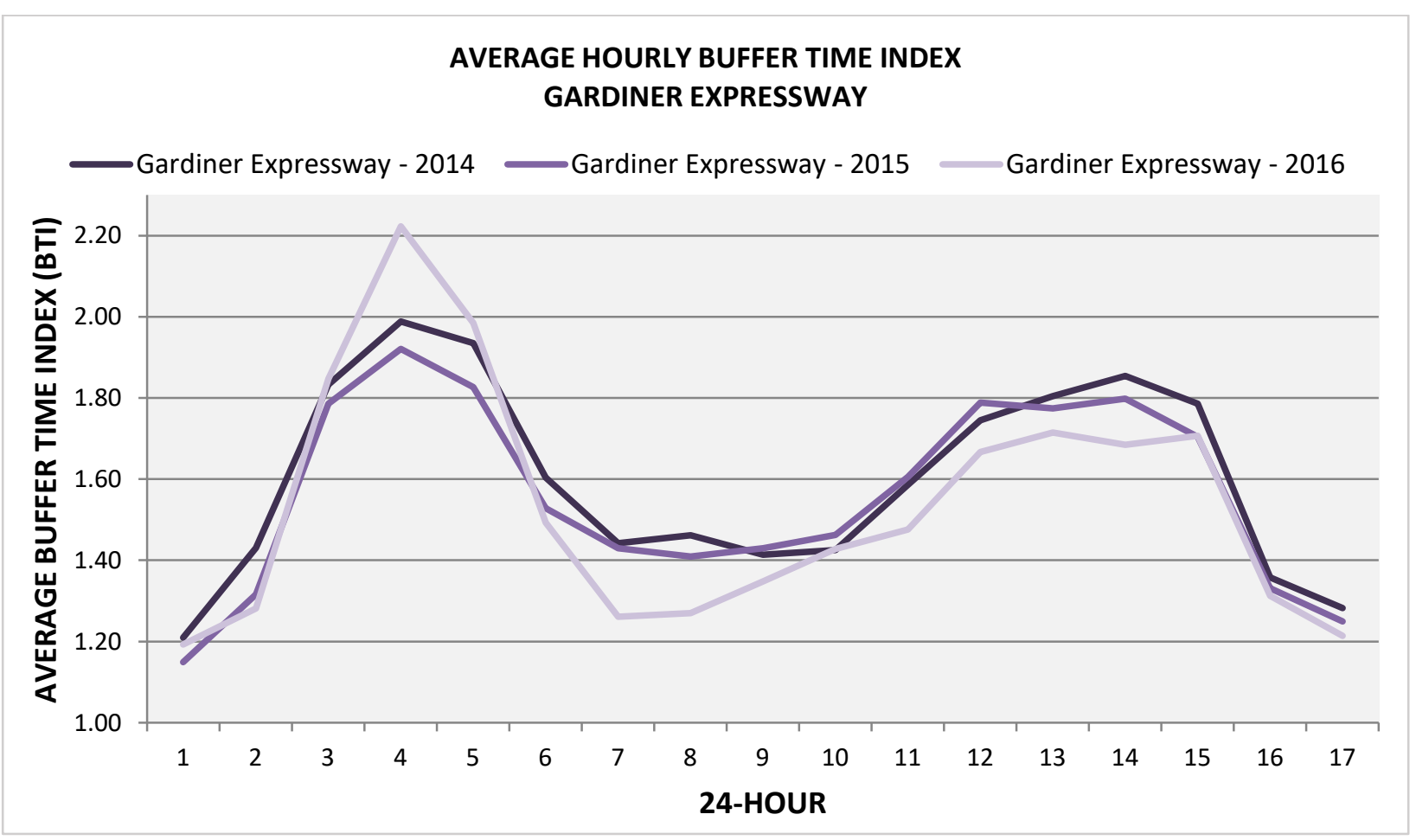

Figure 12: Average Hourly BTI: Gardiner Expressway, 2014-2016. 


\section{Gardiner Expressway Treated vs. Untreated TMCs}

Of the 51 TMCs in the Gardiner Expressway, 19 TMCs received treatment during Intervention 1, and 4 TMCs received treatment during Intervention 2. These are equivalent to 12.84 link-miles and 4.04 linkmiles, respectively. Congestion and travel reliability data for the treated and untreated groups of each intervention was aggregated to unique hours of the day (5am to $9 \mathrm{pm})$, on typical weekdays, for each month of the year. Treated TMCs were much more congested on average for both interventions, but more reliable for Intervention 2 (Figures 13-16 and Table 5).

The monthly speed and buffer time index profiles for Intervention 1 and Intervention 2 reveal the impact of the lane closures. For Intervention 1, treated TMCs were notably outperformed by untreated TMCs prior to, during, and following lane closures, with the most significant differences occurring during the first and second month of the capacity restriction (Figures 13 and 15). When the lanes reopened in Month 13, speeds increased by nearly $8 \mathrm{mph}$ overall and reliability considerably improved (Figure 13).

Regarding Intervention 2, congestion follows the same trend of Intervention 1, wherein the slowest speeds were observed immediately following the lane closure. For Intervention 2, eastbound treated and untreated links of the Gardiner Expressway experience near-identical, trivial impacts on congestion (Figure 14). In contrast, westbound treated TMCs were severely impacted by the lane-closure. In Month 1 of Intervention 2, the average speed of westbound treated TMCs is nearly 20 mph slower than that of untreated TMCs. All throughout the capacity reduction period, untreated links consistently outperform the treated by over $10 \mathrm{mph}$ (Figure 14). Interestingly, the treated TMCs were more reliable than the untreated TMCs on average (Figure 15). However, it must be noted that in the midst of Month 3 of Intervention 2, the westbound lane was reopened, resulting in sudden improvements in unreliability for treated links (Figure 16). Additionally, the low number and link-miles of treated TMC observations in comparison to untreated observations for the second intervention may influence the higher reliability of treated links. 


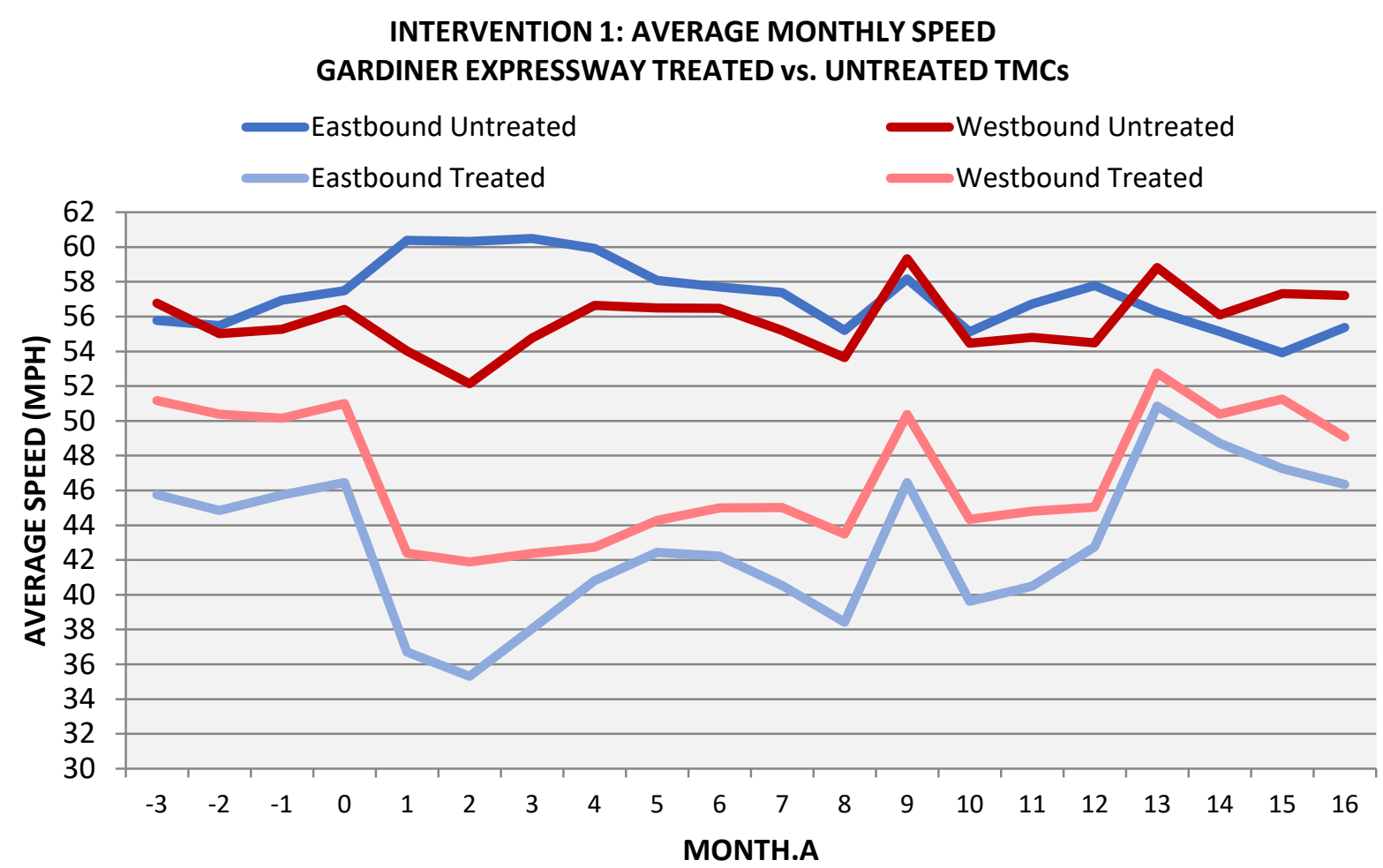

Figure 13: Intervention 1: Average Monthly Speed: Treated vs. Untreated TMCs.

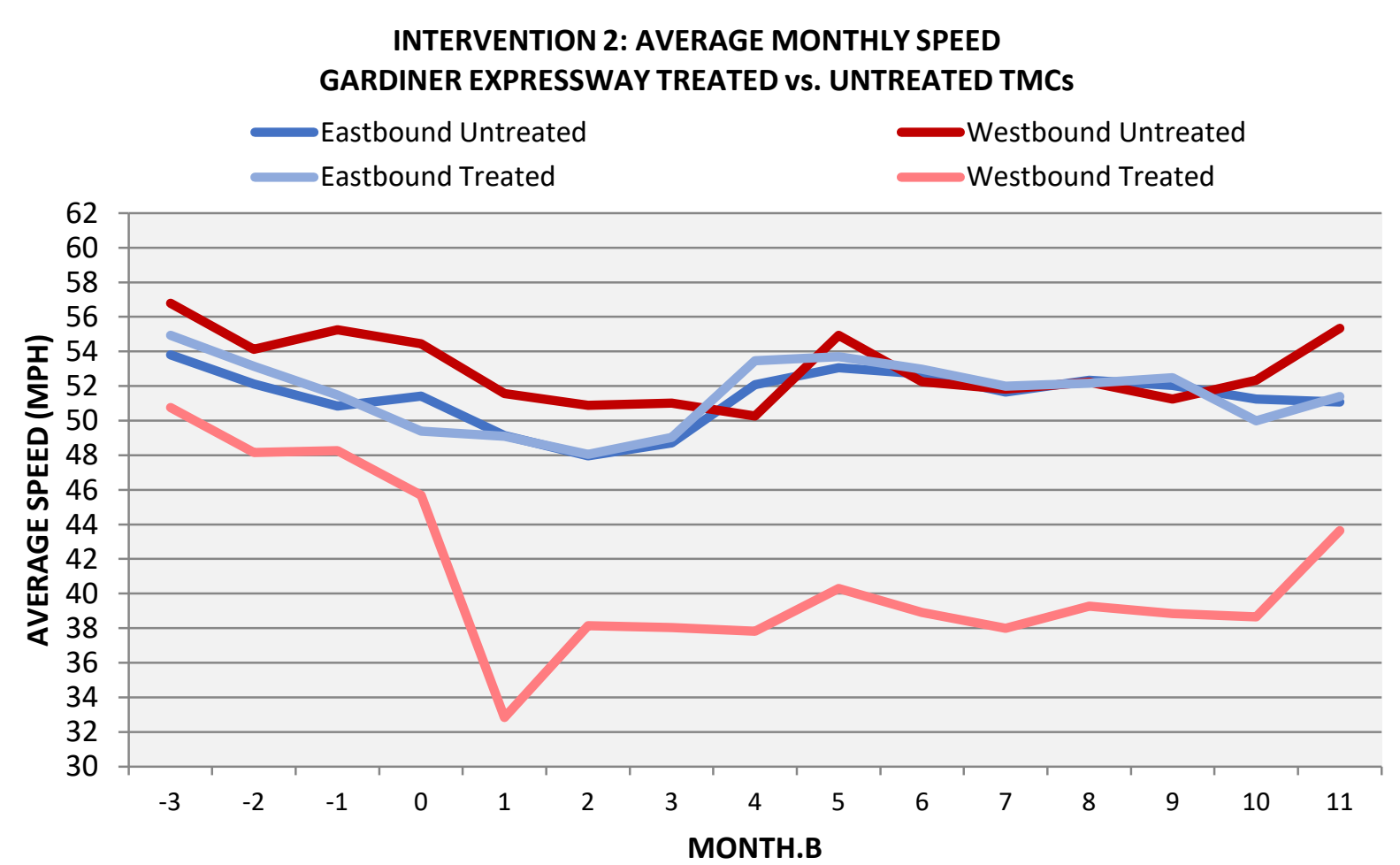

Figure 14: Intervention 2: Average Monthly Speed: Treated vs. Untreated TMCs. 


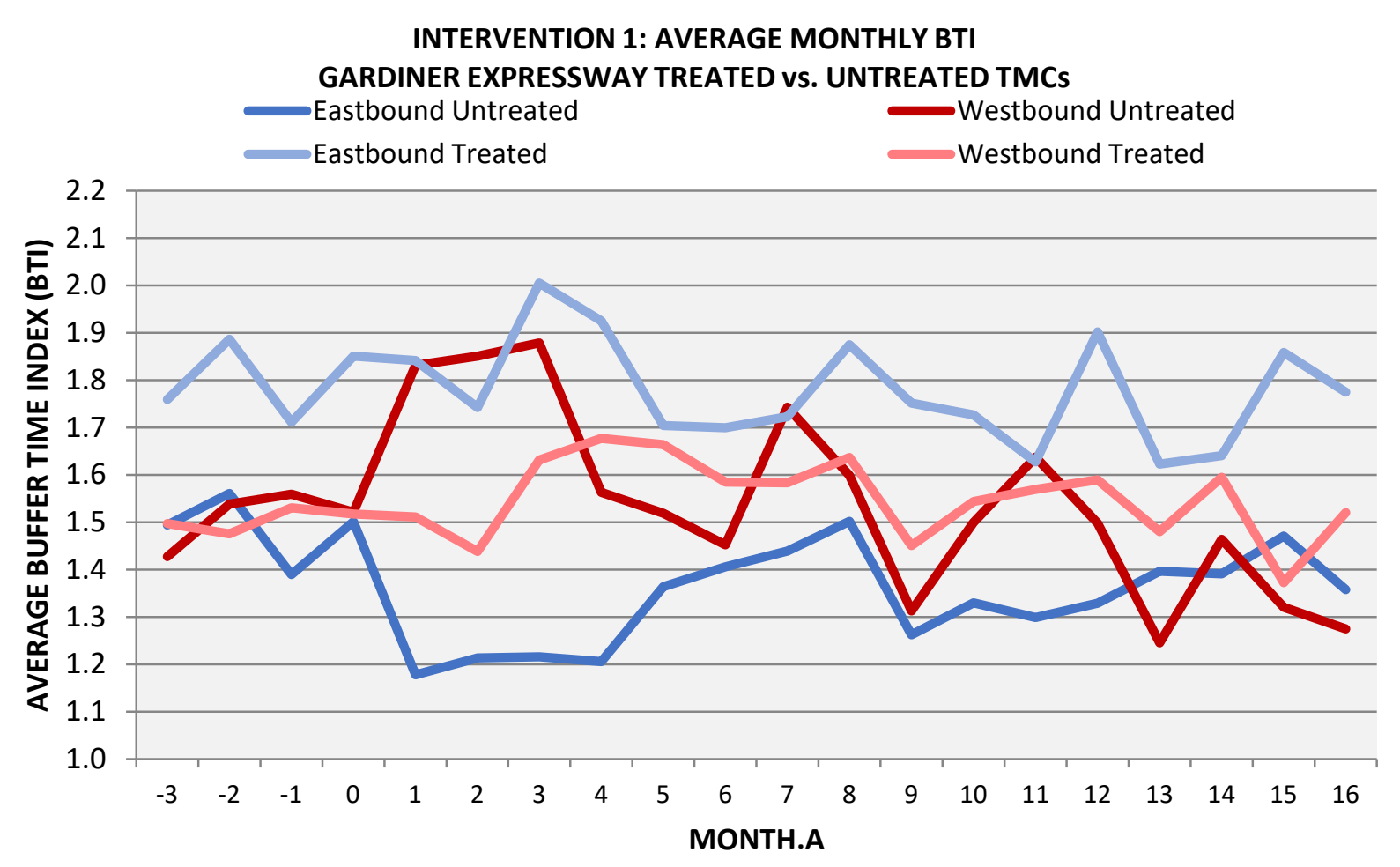

Figure 15: Intervention 1: Average BTI: Treated vs. Untreated TMCs.

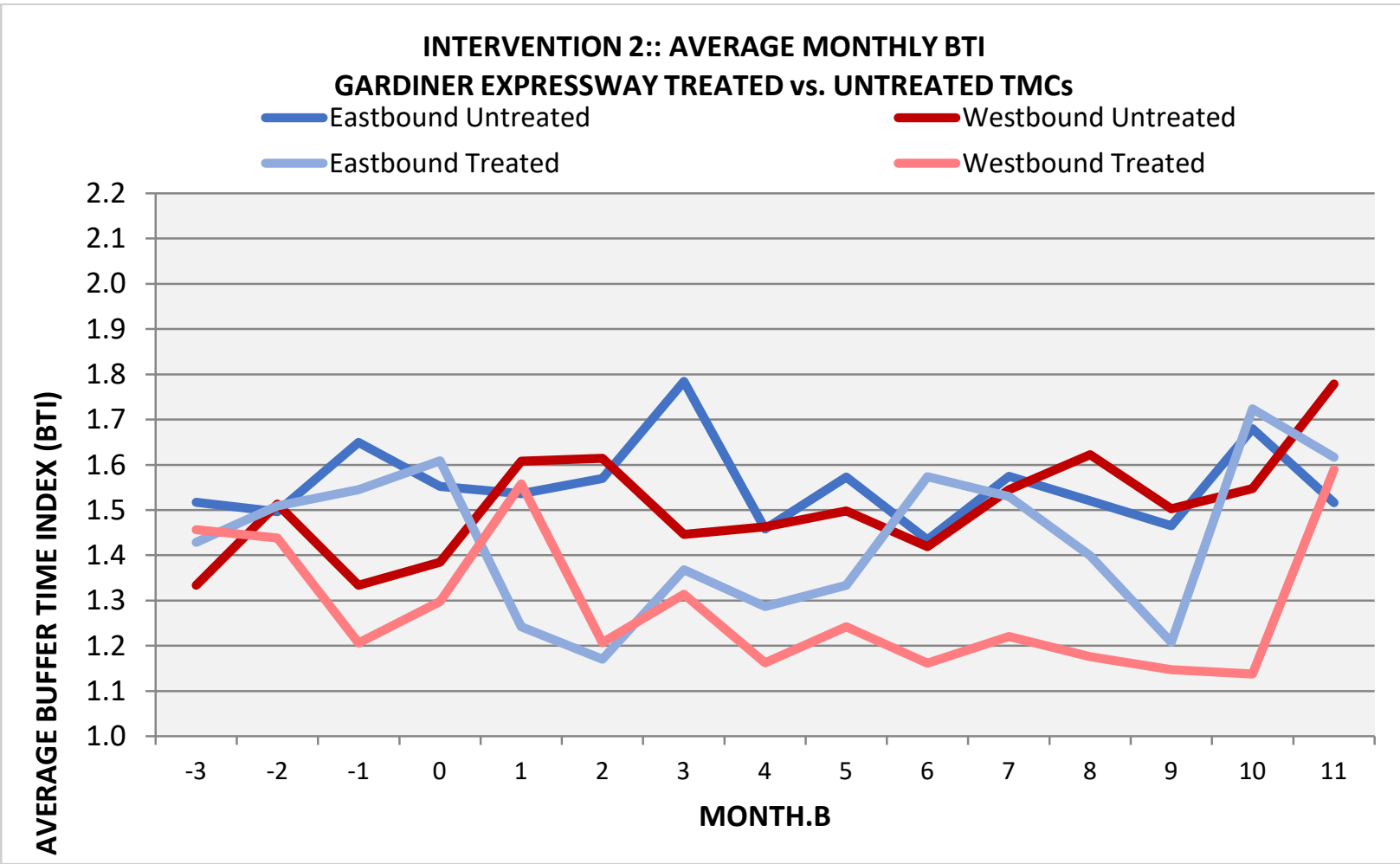

Figure 16: Intervention 2: Average BTI: Treated vs. Untreated TMCs. 
Importantly, the graphs provide insight to how the links between capacity constraints and congestion and reliability change over time on the Gardiner Expressway. For instance, an apparent three-month lane closure adjustment period is observed for Intervention 1, as the average speeds and buffer time index approach a new equilibrium beginning in Month 4 (Figures 13-16).

Table 5: Intervention 1: Average Speeds (AVG) (mph) and BTIs: Monday to Friday, 5AM - 9PM.

\begin{tabular}{|c|c|c|c|c|c|c|c|c|c|c|c|c|}
\hline & \multicolumn{4}{|c|}{ Intervention 1 } & \multicolumn{5}{c|}{ Intervention 2 } \\
\cline { 2 - 14 } & \multicolumn{3}{|c|}{ Speed } & \multicolumn{3}{c|}{ BTI } & \multicolumn{3}{c|}{ Speed } & \multicolumn{3}{c|}{ BTI } \\
\cline { 2 - 14 } & East & West & AVG & East & West & AVG & East & West & AVG & East & West & AVG \\
\hline Treated & 42.99 & 46.89 & 44.94 & 1.78 & 1.54 & 1.66 & 51.55 & 41.15 & 46.35 & 1.44 & 1.29 & 1.36 \\
\hline Untreated & 57.18 & 55.77 & 56.48 & 1.37 & 1.54 & 1.45 & 51.34 & 52.96 & 52.15 & 1.56 & 1.51 & 1.53 \\
\hline
\end{tabular}

Comparisons between the Gardiner Expressway and Highway 401 reveal the strength of the experimental and control groups used for models in this study. Evaluating these highways in the context of the City of Toronto's highway system provides a better understanding of asset performance. Moreover, descriptive statistics reveal the differences in congestion and travel reliability experienced by treated and untreated TMC links for the Gardiner. However, due to the restricted periods of analysis in the study, it is difficult to determine the long-term effects of lane closures and their impacts on congestion and travel reliability. Although there is a three month period (May to July 2015) in which no capacity reductions for construction purposes are in place, and thus the effects of Intervention 1's policy action are evaluated, reduced demand effects cannot be observed with confidence. Due to the occurrence of the Toronto 2015 Pan-Am and Parapan-Am Games, traffic volumes intensified unnaturally during this period and may undermine the results. 


\section{CHAPTER 5: ANALYSIS \& RESULTS}

To conduct the before-after analysis, models using a regression framework were developed for the pre-, peri-, and post-closure test periods of Intervention 1, and pre- and peri-closure test periods of Intervention 2. For both interventions, congestion and reliability models used treated links of the Gardiner Expressway as the experimental group, and Highway 401 links as the control (a total of 106 TMC links, equal to 54.8

miles in length). To further investigate how policy actions affect congestion and travel reliability during peak travel periods, peak-AM (6am to $10 \mathrm{am})$ and peak-PM (3pm to $7 \mathrm{pm})$ models were created. For Intervention 1 models, the experimental group consisted of 19 treated TMC links, totalling 12.8 miles. The experimental group for Intervention 2 models included only 4 TMC links, totalling 4.0 miles (Model 1 in Table 2, Table 6 and 7). The low number of experimental group observations needs to be kept in mind when interpreting results, especially in the case of Intervention 2 models.

Analysis were conducted using a variety of specifications, according to which combination of treated and untreated sections of the Gardiner Expressway and Highway 401 links comprised the experimental and control groups (Table 8). For example, to assess whether congestion and travel reliability results were sensitive to bottlenecks on untreated sections of the Gardiner, Highway 401 links were used as the control. This ensured an isolated control group, and that treated section results were evaluated independently of potential effects on links downstream and upstream from a lane closure area.

Early on, Model 2 in Table 8 had been developed to increase the size of the control group. However, due to the proximity of untreated TMCs to treated TMCs on the Gardiner, background trends were overstated and the results were predisposed to bottleneck effects. These implications led to the development of Model 1, with Model 3 developed to validate the findings of Model 1. In utilizing TMCs (both treated and untreated) of the Gardiner as the experimental group, and Highway 401 TMCs as the control group, the congestion and reliability model results were confirmed to be localized effects (upon the treated sections) and not systemic (Model 3 in Table 8). 
Table 6: Model 1 TMC-link Counts for Interventions.

\begin{tabular}{|c|c|c|c|c|c|c|}
\hline \multirow{2}{*}{} & \multicolumn{3}{|c|}{ Intervention 1: } & \multicolumn{3}{c|}{ Intervention 2: } \\
& April 28, 2014 to April 22, 2015 & August 19, 2015 to June 23, 2016 \\
\hline EAST & WEST & TOTAL & EAST & WEST & TOTAL \\
\hline Highway 401 & 53 & 53 & 106 & 53 & 53 & 106 \\
\hline Gardiner Treated & 9 & 10 & 19 & 2 & 2 & 4 \\
\hline Gardiner Untreated & 14 & 18 & 32 & 21 & 26 & 47 \\
\hline Gardiner Total & 23 & 28 & 51 & 23 & 28 & 51 \\
\hline
\end{tabular}

Table 7: Model 1 TMC-link Lengths (miles) for Interventions.

\begin{tabular}{|c|c|c|c|c|c|c|}
\hline \multirow{2}{*}{} & \multicolumn{3}{|c|}{ Intervention 1: } & \multicolumn{3}{c|}{ Intervention 2: } \\
& April 28, 2014 to April 22, 2015 & August 19, 2015 to June 23, 2016 \\
\hline EAST & WEST & TOTAL & EAST & WEST & TOTAL \\
\hline Highway 401 & 27.41 & 27.36 & 54.77 & 27.41 & 27.36 & 54.77 \\
\hline Gardiner Treated & 6.26 & 6.58 & 12.84 & 2.02 & 2.02 & 4.04 \\
\hline Gardiner Untreated & 6.29 & 7.84 & 14.13 & 10.54 & 12.40 & 22.93 \\
\hline Gardiner Total & 12.55 & 14.42 & 26.97 & 12.55 & 14.42 & 26.97 \\
\hline
\end{tabular}

Table 8: Model Usage.

\begin{tabular}{|c|c|c|c|}
\hline No. & Experimental Group & Control Group & Usage \\
\hline 1 & $\begin{array}{l}\text { Treated Links of } \\
\text { Gardiner Expressway }\end{array}$ & Highway 401 Links & $\begin{array}{l}\text { - Isolated control group } \\
\text { - Able to assess if results are sensitive to } \\
\text { bottleneck effects }\end{array}$ \\
\hline 2 & $\begin{array}{l}\text { Treated Links of } \\
\text { Gardiner Expressway }\end{array}$ & $\begin{array}{l}\text { Untreated Links of } \\
\text { Gardiner Expressway } \\
\text { and Highway } 401 \\
\text { Links }\end{array}$ & $\begin{array}{l}\text { - } \text { Additional controls, but not isolated } \\
\text { - Potential bottleneck effect and overstated } \\
\text { background trends due to proximity of } \\
\text { untreated TMCs to treated TMCs on the } \\
\text { Gardiner. }\end{array}$ \\
\hline 3 & $\begin{array}{l}\text { Gardiner } \\
\text { Expressway Links }\end{array}$ & Highway 401 Links & $\begin{array}{l}\text { - Determination of study results as localized } \\
\text { or systemic effects }\end{array}$ \\
\hline
\end{tabular}




\section{Congestion Performance}

To evaluate the effect of a policy action on asset performance, average speed (in miles per hour) was used as the measure for traffic congestion. Table 9 displays the average speed for treated TMCs of the Gardiner Expressway in comparison to those of Highway 401. For Intervention 1, the average speeds of the experimental group (treated TMCs of the Gardiner) improved by $9 \%$ between pre- and post-closure periods, while average speeds for the control group (Highway 401 TMCs) worsened by about 6\% (Table 9). As such, the completion of Intervention 1 resulted in less congestion and improved performance on treated TMCs of the Gardiner Expressway, with respect to conditions prior to the lane closures (Figure 17 and Figure 18). Morning and evening peak treatment effects are more pronounced than those of the 5 am to $9 \mathrm{pm}$ period. For the experimental group, peak-AM congestion improved by over $8 \%$ between the pre- and post-closure period, and peak-PM congestion improved by nearly 17\% (Table 9). Congestion performance improvements were stronger in the experimental group than the control, which became more congested post-closure with respect to pre-closure conditions. Intervention 2 results mirror this finding; as the policy action comes to a close, treated Gardiner links begin to outperform those of the control group (Figure 19 and Figure 20). Control groups for both interventions were not as significantly impacted peri-closure, with respect to pre-closure conditions, as the experimental group. For instance, changes in average speed for the $5 \mathrm{am}$ to $9 \mathrm{pm}$ period of the control group improve by $4.6 \%$ for Intervention 1, and by $0.5 \%$ for Intervention 2 (Table 9).

Table 9: Average Change in Speed (\%) between the Control Group and Experimental Group.

\begin{tabular}{|c|c|c|c|c|c|c|c|}
\hline \multirow{4}{*}{} & & \multicolumn{3}{|c|}{$\begin{array}{c}\text { Experimental Group: } \\
\text { Treated Gardiner TMCs }\end{array}$} & \multicolumn{3}{c|}{$\begin{array}{c}\text { Control Group: } \\
\text { Highway 401 TMCs }\end{array}$} \\
\cline { 2 - 8 } & \multirow{2}{*}{ Period } & $\begin{array}{c}\text { Pre- } \\
\text { Closure }\end{array}$ & $\begin{array}{c}\text { Peri- } \\
\text { Closure }\end{array}$ & $\begin{array}{c}\text { Post- } \\
\text { Closure }\end{array}$ & $\begin{array}{c}\text { Pre- } \\
\text { Closure }\end{array}$ & $\begin{array}{c}\text { Peri- } \\
\text { Closure }\end{array}$ & $\begin{array}{c}\text { Post- } \\
\text { Closure }\end{array}$ \\
\hline \multirow{2}{*}{$\begin{array}{c}\text { Intervention } \\
1\end{array}$} & 5 AM-9PM & -1.75 & -20.72 & +7.28 & +0.93 & -3.66 & -5.68 \\
\cline { 2 - 8 } & Peak-AM & -3.37 & -19.45 & +5.89 & +5.89 & +2.19 & +0.33 \\
\cline { 2 - 8 } & Peak-PM & -1.03 & -16.11 & +15.92 & -2.94 & -10.53 & -11.16 \\
\hline \multirow{2}{*}{ Intervention } & SAM-9PM & -2.85 & -17.67 & -- & -5.24 & -5.76 & -- \\
\cline { 2 - 8 } 2 & Peak-AM & -6.09 & -16.81 & -- & -2.52 & -5.10 & -- \\
\cline { 2 - 8 } & Peak-PM & +2.41 & -17.38 & -- & -7.83 & -8.87 & -- \\
\hline
\end{tabular}

During the first month of lane closures for Intervention 1, the treated TMCs of the Gardiner Expressway experienced a decrease in average speeds of over $30 \%$. This significant reduction in speed persisted until Month 4, at which time the congestion equilibrium readjusted and improved by about 10\% (Figure 17). Importantly, in the midst of Month 4 of Intervention 2, the westbound lane reopened, permitting some 
capacity relief and improving average speeds for treatment sections (Figure 19). Although Intervention 2 did not impact congestion as severely as Intervention 1, the overall treatment effect trends mirror each other (Figures 17 and 19). It appears that congestion reaches a new equilibrium approximately three months after the start of both interventions. This is indicative of weakening congestion effects over time, and may suggest the incidence of short-term reduced demand effects. This is supported by the graphs presented in Figures 17 to 20 which display changes in congestion over time. Expectantly, average speeds strongly improved following the reopening of the lanes in Month 13 for the experimental group of Intervention 1, and gradually improved as time passed for Intervention 2 (Figure 17 and 20). However, an immediate increase in congestion is experienced two months after lanes reopen following Intervention 1 , particularly in the peak-AM period. This result is likely attributable to the activities of the Toronto 2015 Pan-Am and Parapan-Am Games.

Seasonality effects can be observed in looking at the background trends. Of particular interest is Month 9 in Figures 17 and 18, wherein average speeds for the experimental group spiked during the typical weekday and morning peak for Intervention 1. Month 9 spans the holiday season, and thus this occurrence may be partially attributable to fewer vehicles being on the road at the time, resulting in higher average speeds. Likewise, Month 5 of Intervention 2 spans mid-December to mid-January. In Figure 19 and 20, a sudden increase in average speed for a typical weekday and during both the morning and evening peaks is observed.

Overall, the policy action has proven to be effective in improving congestion performance on the Gardiner Expressway. Although lane closures result in increased congestion peri-closure, there is significant improvement in overall system performance for the experimental group post-closure. In other words, conditions on the Gardiner are better than what they had been prior to the lane closures being implemented. However, it remains unanswered if the overall reduction in congestion following Intervention 1 can be entirely described as an effect of the policy action. Reduced demand resulting from a prolonged period of capacity restrictions may have caused traffic to "disappear" and congestion to consequently improve. Changes in the total number of Gardiner Expressway users pre-, peri-, and postclosure are unknown, but descriptive statistics reveal that commuters were likely to have used alternate routes during interventions (see Chapter 4: Data Overview). Thus, although results are unable to confirm reduced demand effects with certainty, they surely cannot reject them. 


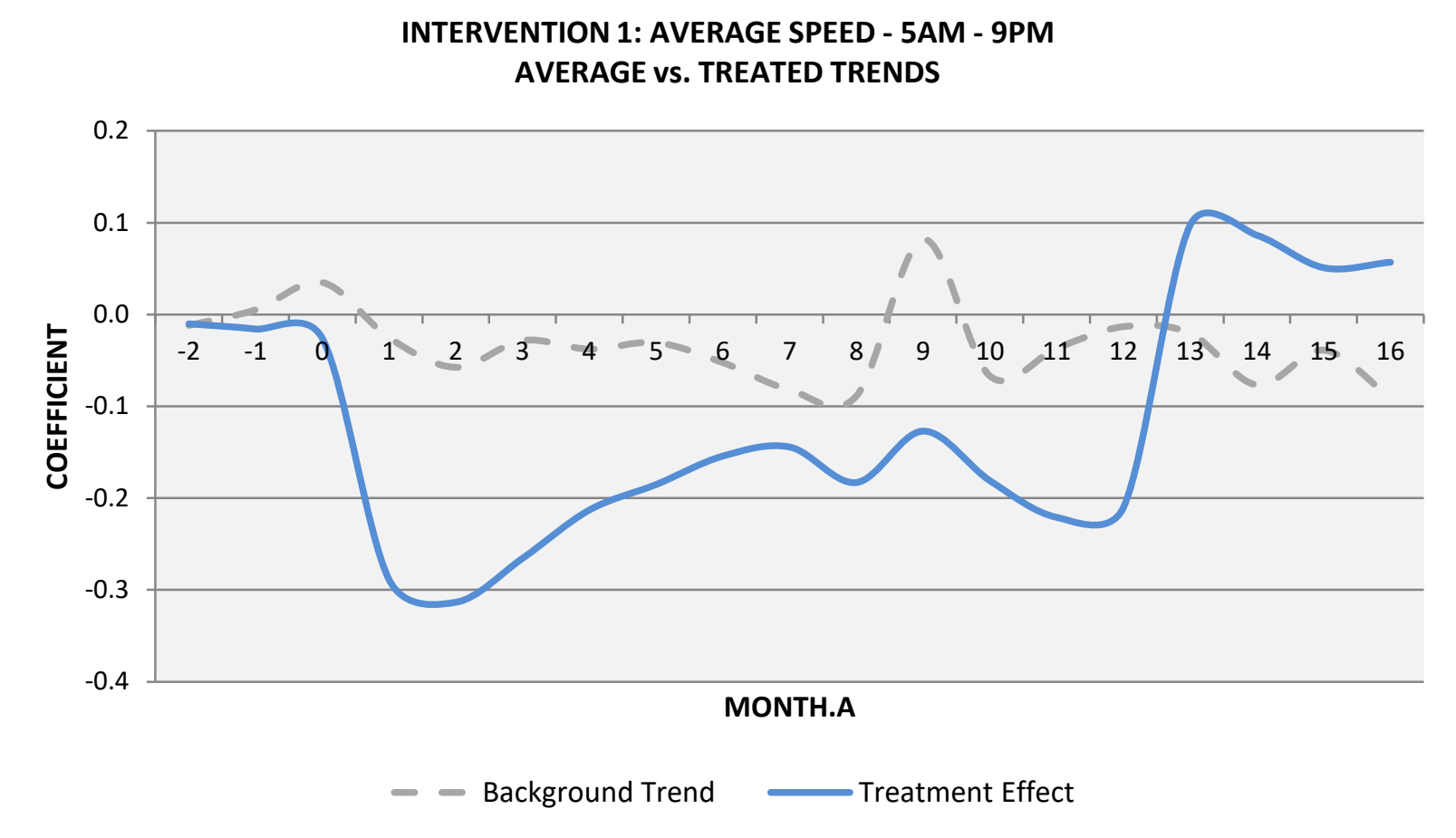

Figure 17: Intervention 1: Average Speed - Average vs. Treated Trends.

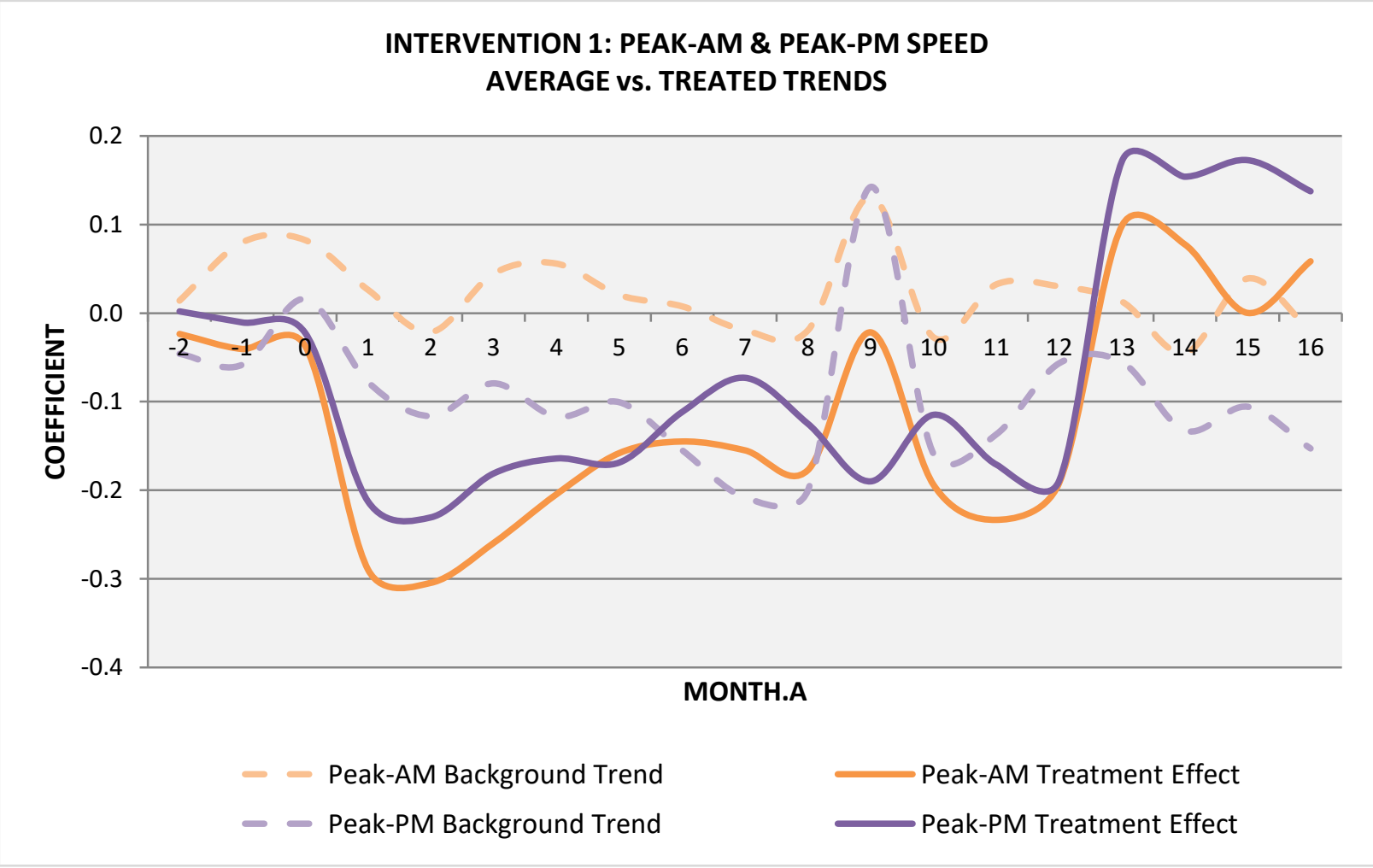

Figure 18: Intervention 1: Peak-AM \& Peak-PM Speed - Average vs. Treated Trends. 


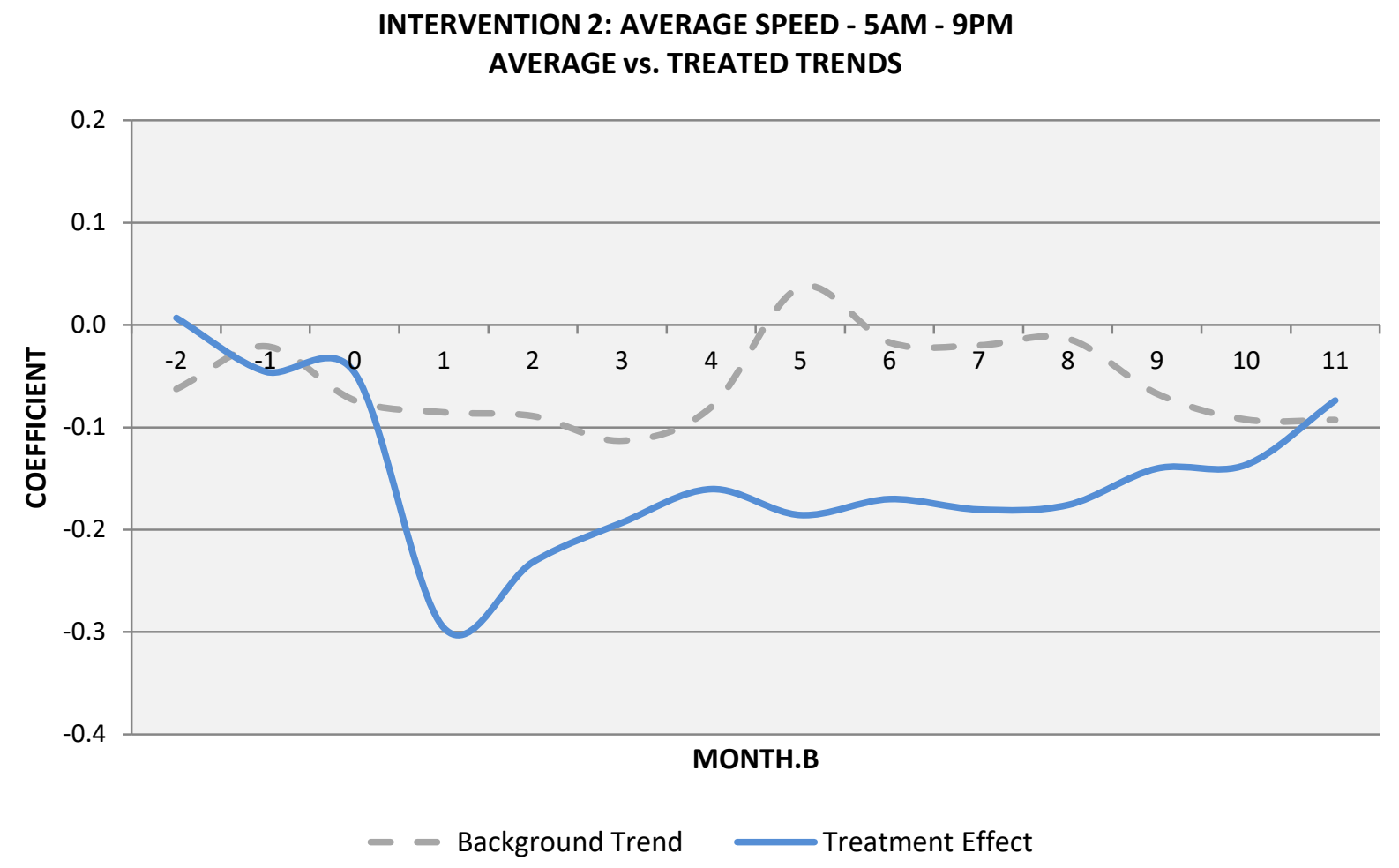

Figure 19: Intervention 2: Average Speed - Average vs. Treated Trends.

INTERVENTION 2: PEAK-AM \& PEAK-PM SPEED

AVERAGE vs. TREATED TRENDS

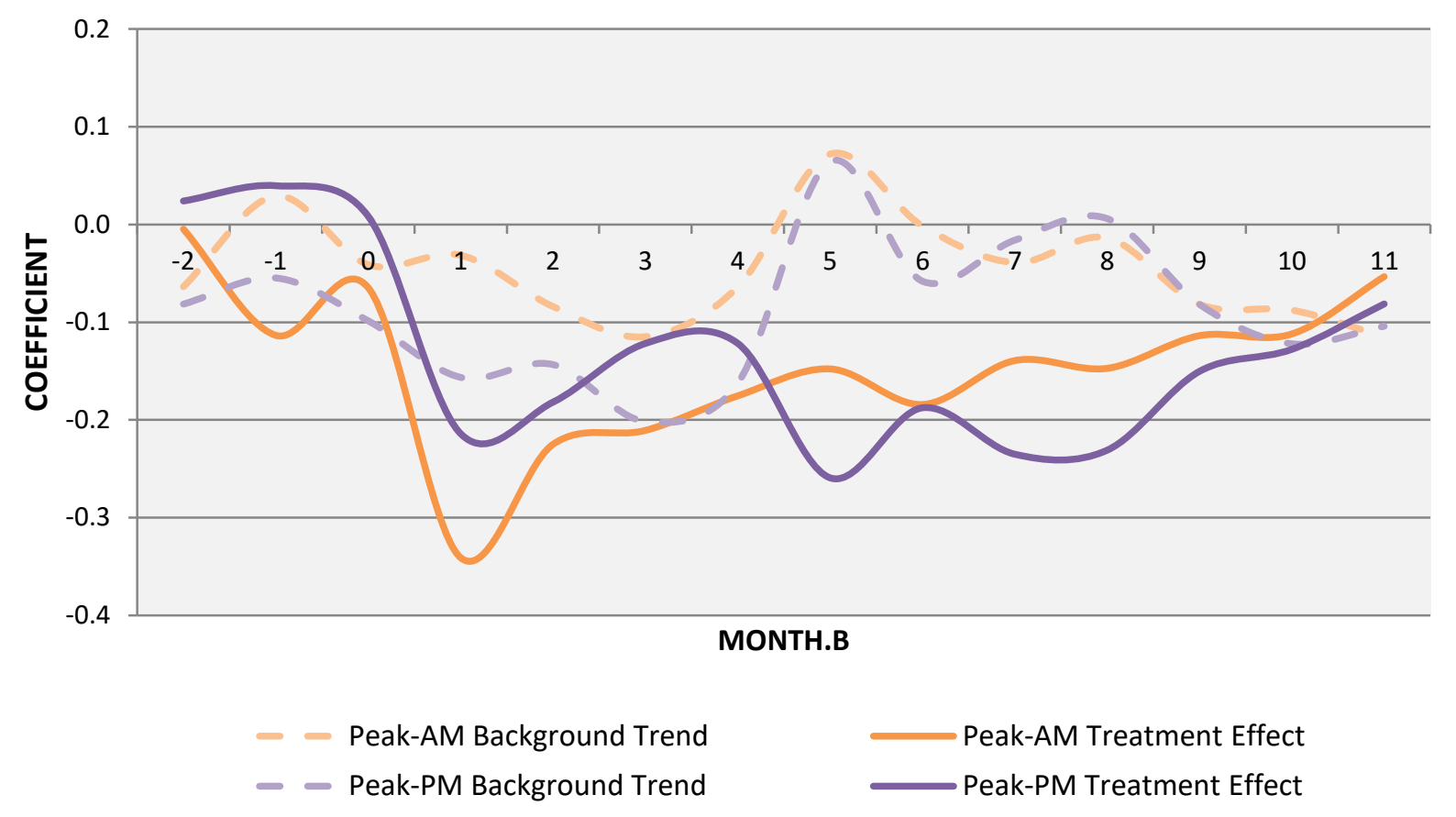

Figure 20: Intervention 2: Peak-AM \& Peak-PM Speed - Average vs. Treated Trends. 


\section{Reliability}

Changes in the buffer time index were measured to investigate the effects on lane closures on travel reliability. Table 10 displays the average buffer time index for treated TMCs of the Gardiner Expressway and those of Highway 401 TMCs. For Intervention 1, the buffer time index for the experimental group increased by less than $1 \%$ between pre- and post-closure periods, while the control group's BTI improved by almost $4 \%$ in the same period. Following the completion of Intervention 1, treated TMCs of the Gardiner Expressway became marginally less reliable in comparison to pre-closure conditions, despite increased travel reliability during the closure period.

Seasonal patterns in the BTI were not clear (Figure 21 and Figure 23). For Intervention 1, the treatment effect moved in the opposite direction of the background trend before, during, and after the policy action. For instance, Month 7 of Intervention 1 was least reliable for the control group, but most reliable for the experimental group (Figure 21). Morning and evening peak trends mirror these results, with the evening peak being more reliable than the morning peak on average for the experimental group, with respect to the control group (Figure 22). These findings could be indicative of links between the Gardiner's treated and untreated sections.

For Intervention 2, the experimental group is almost consistently more unreliable than the control group, with exceptions in Months 0 and 11 (Figure 23). Prior to and during Intervention 2 closures, unreliability decreased overall for the experimental group, but remained steady for the control group (Table 10, Figure 23 and Figure 24). As lane closures continued, the unreliability of treated TMCs of the Gardiner slowly increased, and by Month 11 they were as unreliable as Highway 401 TMCs. Stronger effects on reliability are observed for the AM-peak than PM-peak. Month 2 is the most reliable on a typical weekday during the morning peak, and Month 4 is most reliable during the evening peak.

Table 10: Average Change in Buffer Time Index (\%) between Control and Experimental Groups.

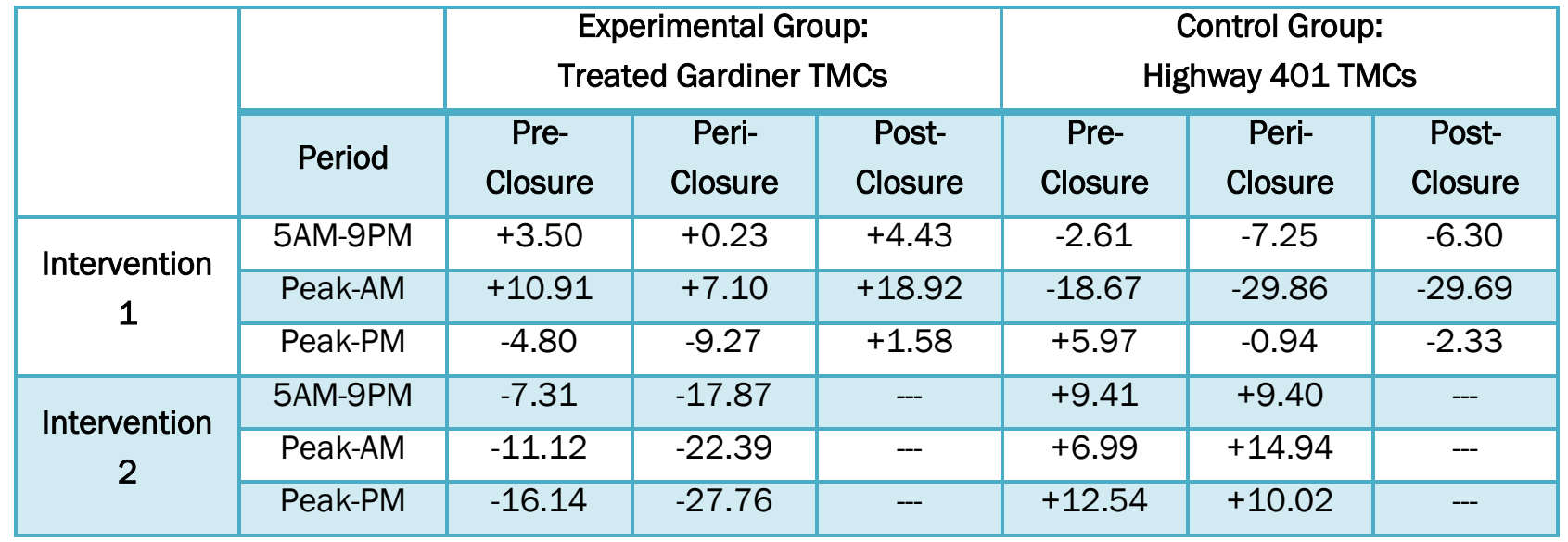




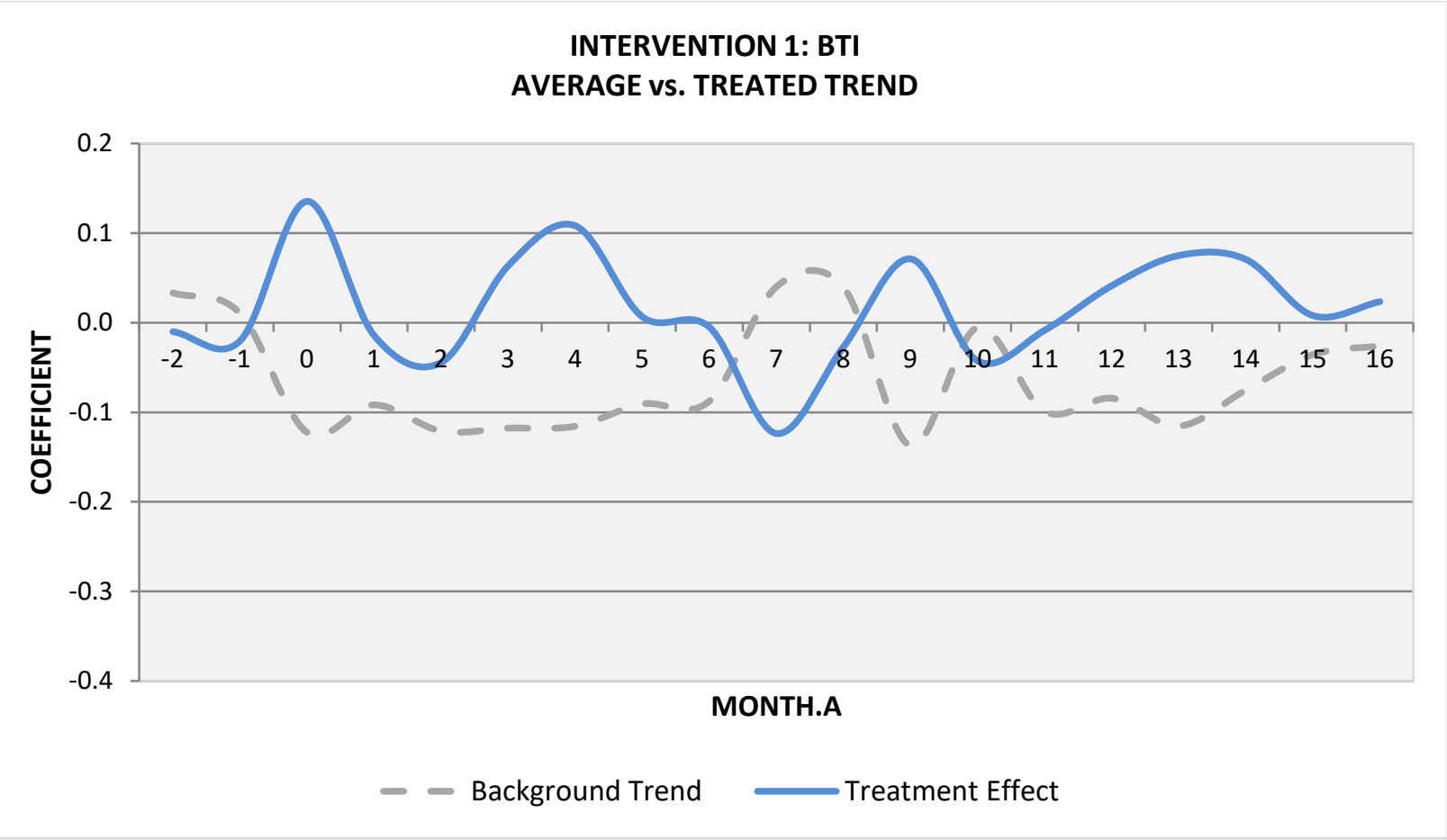

Figure 21: Intervention 1: BTI - Average vs. Treated Trends.

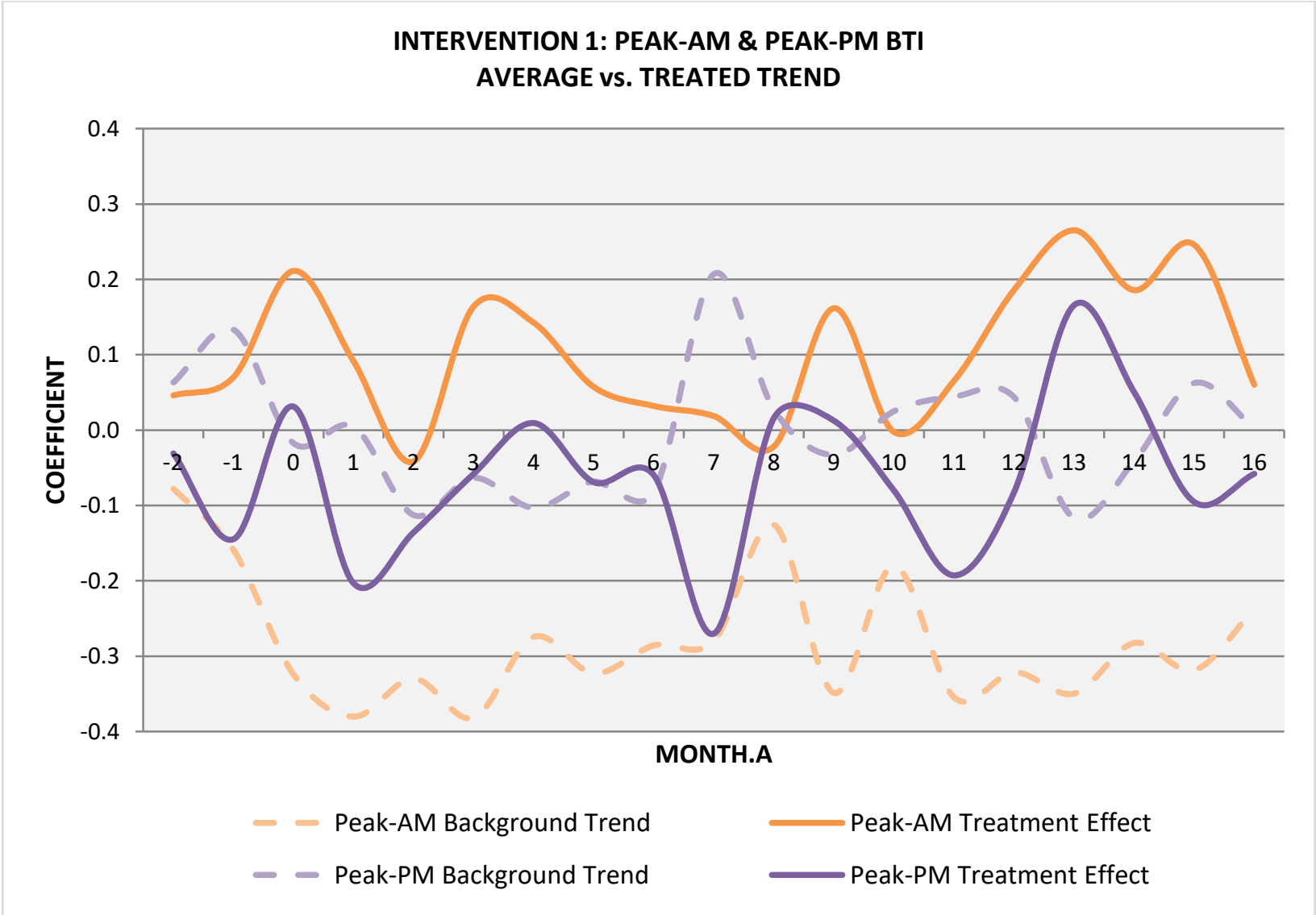

Figure 22: Intervention 1: Peak-AM \& Peak-PM BTI - Average vs. Treated Trends. 


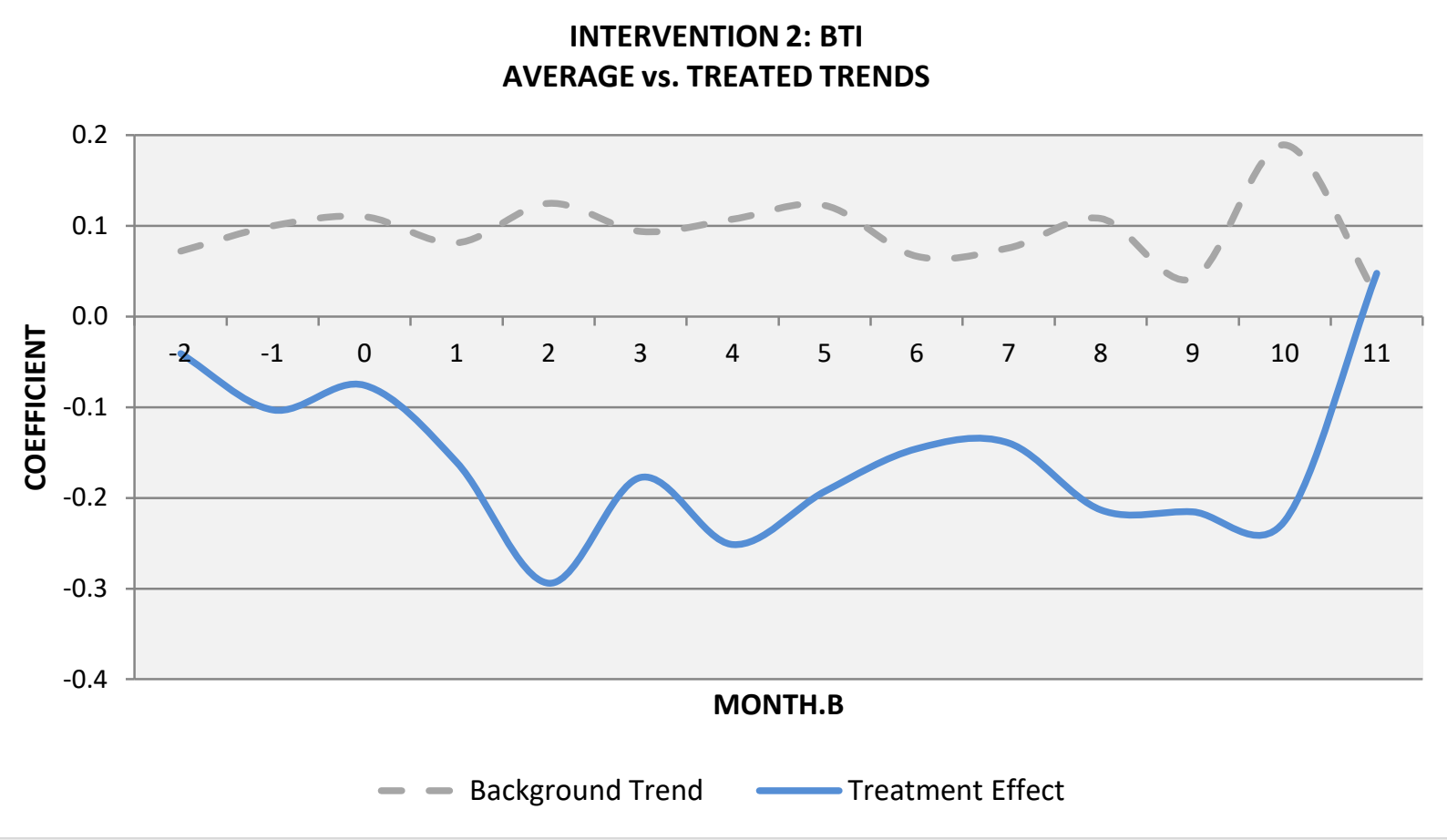

Figure 23: Intervention 2: BTI - Average vs. Treated Trends.

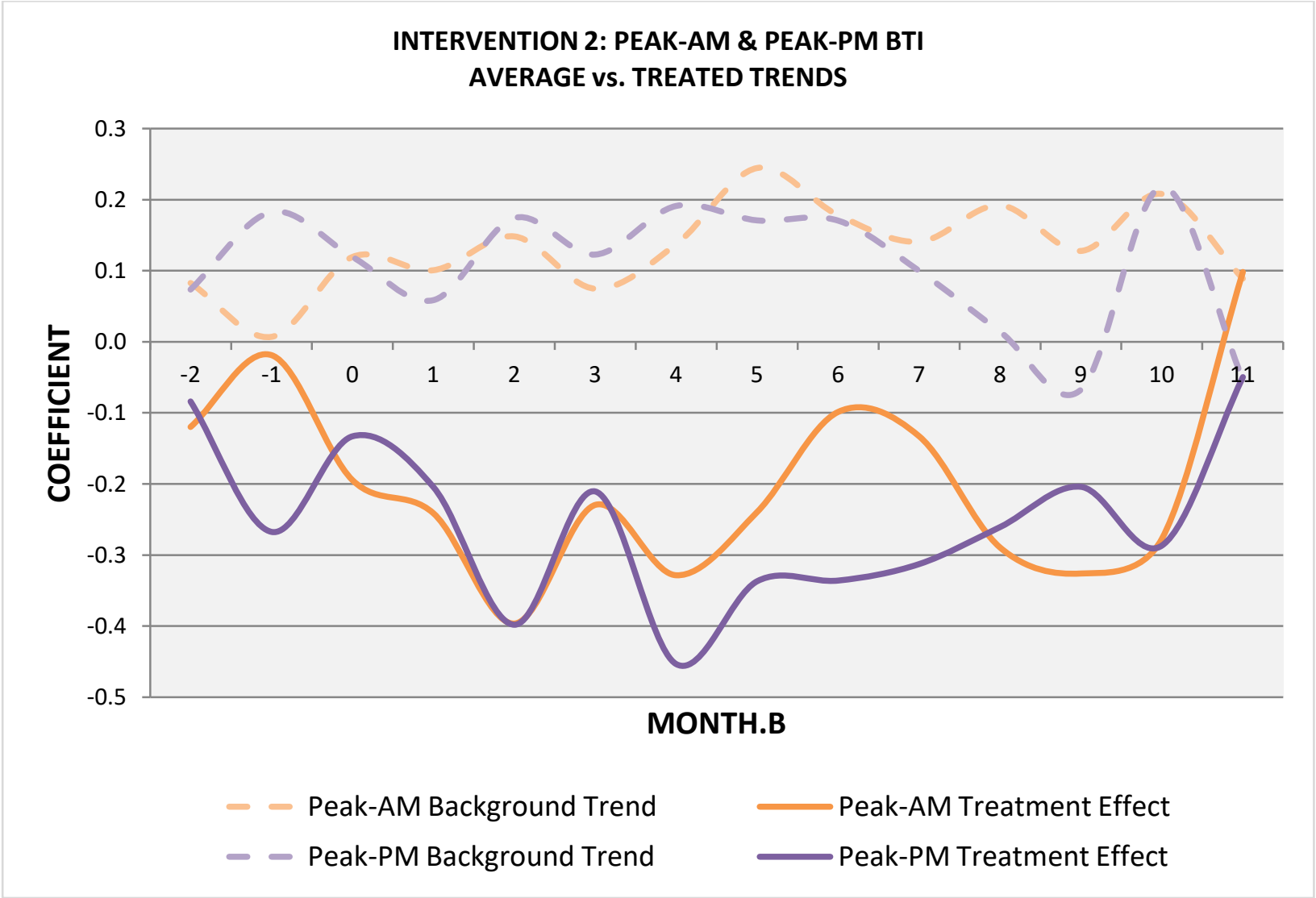

Figure 24: Intervention 2: Peak-AM \& Peak-PM BTI - Average vs. Treated Trends. 


\section{CHAPTER 6: IMPLICATIONS \& CONCLUSIONS}

In all, a before-after analysis using extensive link-based probe data has been applied through a case study of two separate lane closure interventions on the Gardiner Expressway. Research has revealed the effects of prolonged capacity reductions on congestion and travel reliability to be more nuanced than expected. Localized effects on the treated TMCs of the Gardiner Expressway were observed peri- and post-closure, with significant effects on congestion and modest effects on travel reliability. Congestion effects are stronger in the morning and evening peak travel periods, and attenuate over time as a new equilibrium is typically reached following a three-month lane closure adaptation period. Counterintuitively, reliably slower travel is induced during policy actions, as periods of congestion correspond with more reliable travel conditions (reliably slow).

The relationship between congestion and travel reliability is one of association rather than causation. It is often assumed that policy actions, such as lane closures, increase congestion which in turn produces unreliable travel. However, research has shown that this is not the case, and that the two variables move in different directions. During a capacity reduction, although average speeds are greatly reduced resulting in more congestion, reliability improves. Thus, the environment is more reliably slow. Once a policy action is complete and lanes reopen, the added capacity provides short-term congestion relief leading to higher average travel speeds. This period is associated with reduced travel reliability, as differences between average travel speeds and the $95^{\text {th }}$ percentile slowest speeds increase. Reliability and congestion are both key indicators of asset performance, and are prioritized as objectives in major transportation policies such as the City of Toronto's Congestion Management Plan, 2016-2020 (City of Toronto Transportation Services, 2016). Nonetheless, the results of this research suggest congestion and travel reliability may be at odds. Subsequently, policy makers, politicians, and city planners alike need to engage in a value exercise to determine which objective takes precedence.

Research has proven the effectiveness of the two policy actions. Congestion improved postclosure for Intervention 1, with respect to pre-closure conditions, and steadily improved throughout the course of Intervention 2. These results are supported by reduced demand effect literature, as the research provides evidence that a capacity restriction results in short-term congestion increases, with long-term reductions in travel demand (Vanderbilt, 2008; Speck, 2012; Schwartz, 2015; Levinson \& Zhu, 2010). Moreover, the results support the studies of Levinson and Zhu (2010), who documented that traffic stabilizes within two months of the start of a policy intervention. For urban areas, a long-term VMT elasticity, with respect to lane-miles, of 0.9 to 1.0 has been identified (Hanson \& Huang, 1997; Duranton $\&$ Turner, 2011). Yet, the lane closure interventions do not result in new lane-miles being added to the system. Rather, lane-miles are removed for a period of time and then later reintroduced. As a result, induced demand effects cannot be identified with certainty. Although short-term congestion relief is 
observed following the reopening of the lanes, it is anticipated to dissipate over time until conditions are no different than those prior to closure.

In regards to reliability, significant change in performance between pre- and post-closure conditions was not achieved. Depending on how one value's congestion and reliability, the interventions may or may not be viewed as successful in improving the overall performance of the Gardiner. From an asset manager perspective, the major transport investment was worth it as the policy actions were a victory in the fight against congestion. Yet, the question of whether or not municipalities should add or remove capacity from major highways remains unanswered. The literature review identified the effects of reduced demand and highlighted real-world examples of its success. In support of this phenomenon, this research indicates that in the event of a prolonged capacity restriction, congestion steadily improves and appears to reach a new equilibrium within a three-month period. For Intervention 1, this improvement is significant, as average speeds increase by nearly $10 \%$. Even once a new equilibrium is established, congestion continues to improve little by little. This effect is most pronounced in Intervention 2, wherein a clear, positive increase in average speeds is apparent (Figure 19). As such, results suggest that congestion is likely to gradually improve until conditions were no different than those prior to closure if the lanes had never reopened.

The period necessary for congestion to bounce back to pre-closure levels following a permanent capacity reduction on an asset is unknown. Since the time needed by commuters to adjust travel behaviour varies by the individual, it falls on municipalities to support or discourage such a change. It has been proven that a reduction in highway capacity has the potential to improve system performance and reduce demand in some facility. Thus, it is up to cities to identify their values and make the right choice in regards to congestion mitigation strategies and planning and managing major transportation assets. When capacity is added, congestion is relieved in the short-term, but reaches a new, higher equilibrium in the long-term (Litman, 2017). When capacity is removed, congestion immediately increases. However, the size of this increase gradually reduces as time passes as a result of reduced demand. Provincial and municipal transportation planners have provided commuters with an extensive road and public transit network, thereby offering an endless variety of options to reach a destination in the region. With these factors in mind, the necessity of maintaining an expensive, traffic-clogged highway is questioned. It must be determined if a highway is truly needed or exists exclusively for commuter convenience. This in turn prompts discussion on who should bear the cost of maintenance and the price of congestion if an asset is considered critical to the success of the city.

Without congestion pricing, traffic will continue to grow. Although increasing road capacity is a short-sighted policy to combat congestion, relying on the effects of reduced demand to come to fruition may be an even riskier endeavor. This is the tipping point on which the City of Toronto currently sits. The City is the asset manager of a regionally significant highway. With impeding growth in the region, usage of the Gardiner is anticipated to increase, as will the costs for repairs and maintenance. Congestion 
solutions need to be implemented now to avoid increased expenditures in the future. Overall, conclusions for policymaking depend on norms and values. If policymakers value climate change objectives and sustainable practices over commuter convenience and short-term traffic alleviation, congestion management approaches should include reductions in major roadway capacity. However, if short-term travel time benefits are valued above all and policymakers seek to support automobility through the provision of capacity, congestion alleviation strategies should include road usage charges. Without an approach which incurs a cost on users of an asset, traffic will be generated as a result of induced demand and rapidly grow to be no better than levels prior to a capacity expansion. Seeing as the Gardiner is owned and operated by the City, the City should have the right to impose user fees on commuters in the form of congestion charges. In doing so, a congestion management strategy will be adopted alongside a new revenue generation tool. In short, if the City has a mandate to reduce congestion and views the Gardiner as a critical piece of transportation infrastructure, a road toll is the ideal tool for the job. 


\section{REFERENCES}

(2016, December 3). “Toronto residents and 905ers debate Mayor John Tory's road tolls”. Toronto Star. Retrieved from https://www.thestar.com/opinion/letters_to_the_editors/2016/12/03/torontoresidents-and-905ers-debate-mayor-john-torys-road-tolls.html.

Barnes, J. (2012, October 23). Take Away the Mystery of Regression vs. ANOVA. All Analytics: The Community for Data Management, Business Intelligence, and Analytics. Retrieved from http://www.allanalytics.com/author.asp?section_id=1413\&doc_id=252823.

Boarnet, M., and Chalermpong, T. (2000, December). New highways, urban development, and induced travel. Institute of Transportation Studies. Irvine, CA: University of California.

Caro, R. (1974). The Power Broker: Robert Moses and the Fall of New York. New York, NY: Vintage.

Cervero, R. (2002). Induced travel demand: research design, empirical evidence, and normative policies. Journal of Planning Literature, 17(1), 3-19.

Cervero, R. (2003). Road expansion, urban growth, and induced travel: a path analysis. Journal of the American Planning Association, 69(2), 145-163.

Cervero, R., and Hansen, M. (2000). Road supply-demand relationships: sorting out casual linkages. Institute of Transportation Studies. Irvine, CA: University of California.

City of Seattle. (2008, January). 6 Case Studies in Urban Freeway Removal. Retrieved from https://www.seattle.gov/transportation/docs/ump/06\%20SEATTLE\%20Case\%20studies\%20in\% 20urban\%20freeway\%20removal.pdf.

City of Toronto. (2013, September). Average Weekday, 24 Hour Traffic Volume (Most Recent Counts from 2005-2013). Retrieved from http://www1.toronto.ca/City\%200f\%20Toronto/ Transportation\%20Services/Road\%20safety/Files/pdf/24hourvolumemap2013.pdf.

City of Toronto Transportation Services. (2016). Congestion Management Plan, 2016-2020. Retrieved from https://www1.toronto.ca/City\%200f\%20Toronto/Transportation\% 20Services/TS\%20Publications/Reports/CMP\%202016-2020_Final_Nov20_Web.pdf.

DiManno, R. (2012). “DiManno: Bury the Gardiner to under the mistakes of yesteryear”. The Toronto Star. Retrieved from https://www.thestar.com/news/gta/2012/12/13/ dimanno_bury_the_gardiner_to_undo_the_mistakes_of_yesteryear.html.

Downs, A. (1962). The law of peak-hour expressway congestion. Traffic Quarterly, 16(3), 393- 409.

Downs, A. (1992). Stuck in traffic: Coping with Peak-hour Traffic Congestion. Washington, DC: Brookings Institution Press.

Duany, A., Plater-Zyberk, E., and Speck, J. (2000). Suburban Nation: The Rise of Sprawl and the Decline of the American Dream. New York, NY: North Point Press.

Duranton, G., and Turner, M. (2011). The fundamental law of road congestion: evidence from US cities. American Economic Review, 101(6), 2616-2652. 
Fulton, L., Noland, R., Meszler, D., and Thomas, J. (2000). A statistical analysis of induced travel effects in the U.S. mid-Atlantic region. Journal of Transportation and Statistics, 3(1), 1-14.

Goodwin, P. (1996). Empirical evidence on induced traffic, a review and synthesis. Transportation, 23(1), 35-54.

Handy, S. and Boarnet, M. (2014). Impact of highway capacity and induced travel on passenger vehicle use and greenhouse gas emissions. California Air Resources Board. Retrieved from http://www.arb.ca.gov/cc/sb375/policies/hwycapacity/highway_capacity_bkgd.pdf.

Hanson, M., and Huang, Y. (1997). Road supply and traffic in California urban areas. Transportation Research Part A: Policy and Practice, 31(3), 205-218.

Hymel, K., Small, K., and Dender, K. (2010). Induced demand and rebound effects in road transport. Irvine, CA: University of California.

Giuliano, G., Chakrabarti, S., and Rhoads, M. (2015). Using regional archived multimodal transportation system data for policy analysis: a case study of the LA Metro Expo line. Journal of Planning Education and Practice, 36(2), 195-209.

Jacobsen, P. (1997, May 14). "Liquid vs Gas Models for Traffic”. Los Angeles Times. Retrieved from http://articles.latimes.com/1997-05-14/local/me-58478_1_freeways-capacity-traffic.

Kaatz, V., and Sweet, M. (2016, August 2). Before-After Methods: Theory and Practice. Toronto, ON: Ryerson University School of Urban and Regional Planning.

Kane, L. (2014). “Gardiner Expressway: a brief history of Toronto's ‘superhighway’”. The Toronto Star. Retrieved from https://www.thestar.com/news/gta/2014/02/05/gardiner_ expressway_a_brief_history_of_torontos_superhighway.html.

Leeming, J.J. (1969). Road Accidents: Prevent or Punish?. UK: Cassell.

Levinson, D. and Zhu, S. (2010, July). Traffic flow and road user impacts of the collapse of the I-35W bridge over the Mississippi River. University of Minnesota. St. Paul, MN: Minnesota Department of Transportation.

Litman, T. (2017, January 2). Generated Traffic and Induced Demand: Implications for Transport Planning. Victoria Transport Policy Institute. Retrieved from http://www.vtpi.org/gentraf.pdf.

Mann, A. (2014, June 17). "What's up with that: building bigger roads actually makes traffic worse". Wired. Accessed from https://www.wired.com/2014/06/wuwt-traffic-induced-demand/.

Mokhtarian, P., Samaniego, F., Shumway, R., and Willits, N. (2002). Revisiting the notion of induced traffic through a matched-pairs study. Transportation, 29, 193-202.

Noland, R. (2001). Relationships between highway capacity and induced vehicle travel. Transportation Research Part A: Policy and Practice, 35(1), 47-72.

Rieti, J. (2017, January 27). “Mayor Tory decries 'short-sighted' road-toll rejection by province”. CBC News. Retreived from http://www.cbc.ca/news/canada/toronto/john-tory-road-tolls-1.3954882. 
SACTRA. (1994). Trunk Roads and Generation of Traffic. Standing Advisory Committee on Trunk Road Assessment. London, UK: Her Majesty's Stationery Office.

Schiffer, R., Steinvorth, W., and Milam, R. (2005). "Comparative Evaluations on the Elasticity of Travel Demand". Annual Meeting Paper 05-0313. Washington, DC: Transportation Research Board.

Schwartz, S. (2015). Street Smart: The Rise of Cities and the Fall of Cars. New York, NY: PublicAffairs.

Speck, J. (2012) Walkable City: How Downtown Can Save America, One Step at a Time New York, NY: North Point Press.

STPP. (1998). An Analysis of the relationship between highway expansion and congestion in metropolitan areas. Surface Transportation Policy Project. Retrieved from http://www.transact.org.

The Canadian Press. (2016). Vancouver Traffic Congestion the Worst in the Country: study. The Huffington Post. Retrieved from http://www.huffingtonpost.ca/2016/03/22/vancouvertrafficcongestion_n_9524956.html.

TomTom. (2016). Toronto - Profile City. TomTom Traffic Index: Measuring Congestion Worldwide. Retrieved from http://www.tomtom.com/en_gb/trafficindex/city/TOR.

Vanderbilt, T. (2008). Traffic: Why We Drive the Way We Do (and What It Says About Us. New York, NY: Knopf. 